\title{
Influência do solo e topografia sobre as variações da composição florística e estrutura da comunidade arbóreo-arbustiva de uma floresta estacional semidecidual em Ingaí, MG
}

\author{
REJANE T. BOTREL ${ }^{1}$, ARY T. OLIVEIRA FILHO ${ }^{1,3}$, LUCIENE A. RODRIGUES ${ }^{2}$ e NILTON CURI ${ }^{2}$
}

(recebido: 2 de maio de 2001; aceito: 8 de março de 2002)

\begin{abstract}
Influence of soils and topography on the variations of species composition and structure of the community of trees and shrubs of a tropical semideciduous forest in Ingaí, southeastern Brazil). A survey of the community of trees and shrubs, topography and soils of a fragment of tropical semidecidous forest was carried out with the objective of assessing alleged correlations between the variations in physiognomic structure and species composition and variations in soil water regime and chemical fertility. The forest fragment, with an area of 17 ha is situated on the margin of the river Ingaí $\left(21^{\circ} 24^{\prime} \mathrm{S}\right.$ and $\left.44^{\circ} 55^{\prime} \mathrm{W}\right)$, Ingaí municipality, Minas Gerais state, south-eastern Brazil. A topographic survey and a detailed soil classification were accomplished in the forest area. Individual trees and shrubs with diameter at breast height $(\mathrm{dbh}) \geq 5 \mathrm{~cm}$ were sampled in 25 plots with $20 \times 20 \mathrm{~m}$ of dimensions. Samples of surface soil $(0-20 \mathrm{~cm}$ of depth) were collected from each plot for analyses of chemical and textural properties. The survey registered 2,683 individuals belonging to 140 species, 90 genera, and 41 families, as well as four soil subgroups and six drainage classes. A canonical correspondence analysis (CCA) of the patterns emerging from the environmental variables and species' abundances indicated that these are distributed in the fragment under a strong influence of the water regime and chemical fertility of the soils. Besides, many species produced significant correlations among their abundance in the plots, soil drainage classes and saturation of bases, suggesting that water and mineral nutrients are key environmental variables determining species distribution in the forest.
\end{abstract}

RESUMO - (Influência do solo e topografia sobre as variações da composição florística e estrutura da comunidade arbóreo-arbustiva de uma floresta estacional semidecidual em Ingaí, MG). Foi realizado um levantamento da comunidade arbóreo-arbustiva, da topografia e dos solos de um fragmento de floresta estacional semidecidual com o objetivo de verificar as possíveis correlações entre variações da estrutura fisionômica e composição de espécies e variações do regime de água e

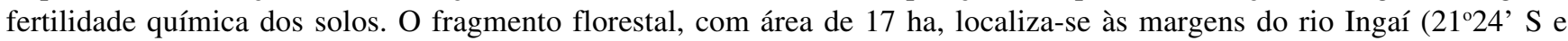
4455' W), no município de Ingaí, MG. Foram realizados um levantamento plani-altimétrico da área e uma classificação detalhada dos solos da floresta. Foram alocadas 25 parcelas de $20 \times 20 \mathrm{~m}$ para amostrar os indivíduos arbóreo-arbustivos com diâmetro à altura do peito (DAP) $\geq 5 \mathrm{~cm}$. Amostras do solo superficial $(0-20 \mathrm{~cm}$ de profundidade) foram coletadas nas parcelas para análises das propriedades químicas e texturais. Foram registrados nas parcelas 2.683 indivíduos distribuídos em 140 espécies, 90 gêneros e 41 famílias, bem como quatro subgrupos de solos e seis classes de drenagem. Uma análise de correspondência canônica (CCA) dos padrões emergentes das variáveis ambientais e da abundância das espécies indicou que estas se distribuem no fragmento sob forte influência do regime de água e da fertilidade química dos solos. Além disso, várias espécies produziram correlações significativas entre sua abundância nas parcelas e as classes de drenagem e saturação por bases dos solos, sugerindo que água e nutrientes minerais são as principais variáveis ambientais determinando a distribuição das espécies na floresta.

Key words - tropical semideciduous forest, riverine forest, community of trees and shrubs, multivariate analysis, soil-vegetation relationship

\section{Introdução}

Entre os diversos tipos florestais encontrados no Brasil, as matas ciliares destacam-se como importantes refúgios para a fauna terrestre e aquática, como

\footnotetext{
1. Universidade Federal de Lavras, Departamento de Ciências Florestais, 37200-000 Lavras, MG, Brasil.

2. Universidade Federal de Lavras, Departamento de Ciências do Solo, 37200-000 Lavras, MG, Brasil.

3._Autor para correspondência: aryfilho@ufla.br
}

corredores de fluxo gênico vegetal e animal e como meios essenciais para a proteção do solo e dos recursos hídricos (Barrella et al. 2000, Lima \& Zakia 2000, Marinho-Filho \& Gastal 2000). Estas matas sofrem impactos naturais causados pelos cursos d'água, tais como erosão e sedimentação, e também são alvos freqüentes da ação antrópica, pois estão localizadas em sítios de fertilidade relativamente superior, muito visados para agricultura (van den Berg \& Oliveira Filho 2000).

A fragmentação florestal, que também atinge as matas ciliares, na maior parte das vezes, ocorre devido 
à substituição de parte da floresta por pastagens e atividades agrícolas. As pressões humanas sobre estas fisionomias têm conseqüências relevantes, principalmente nas regiões onde a atuação dos colonizadores europeus é mais antiga, como ocorreu na Bacia do Alto Rio Grande em Minas Gerais, onde atualmente, da cobertura florestal primitiva, restam somente fragmentos esparsos, em sua maior parte perturbados pelo fogo, pela pecuária extensiva e pela retirada seletiva de madeira (Oliveira Filho et al. 1994a). Desta forma tornase urgente a necessidade de se avaliar a diversidade biológica contida nos atuais fragmentos, sejam eles ciliares ou não, por meio de sua quantificação, bem como compreender a organização espacial da comunidade nos fragmentos face às variações do ambiente e a direção das mudanças nos processos ecológicos, o que permitirá avaliar os potenciais de perdas e conservação dos recursos naturais a longo prazo.

Este trabalho integra o Subprojeto Estratégias para conservação e manejo da biodiversidade em fragmentos de florestas semidecíduas - executado pela EMBRAPA Recursos Genéticos, Universidade Federal de Lavras (UFLA) e Universidade de Brasília (UnB) e integrante do Projeto de Conservação e Utilização Sustentável da Diversidade Biológica Brasileira (PROBIO) supervisionado pelo Ministério do Meio Ambiente (MMA), gerido pelo Conselho Nacional de Desenvolvimento Científico e Tecnológico (CNPq) e apresentado pelo governo brasileiro ao GEF/BIRD.

$\mathrm{O}$ presente trabalho foi desenvolvido em um fragmento de floresta estacional semidecidual no município de Ingaí, sul de Minas Gerais, com o objetivo de verificar as possíveis correlações entre as variações da estrutura fisionômica e da diversidade e composição de espécies da comunidade arbóreo-arbustiva e as variações ambientais relacionadas com o substrato, aqui compreendido como o conjunto de variáveis topográficas e edáficas que determinam o status nutricional mineral e o regime de água dos solos. Como o fragmento encontra-se no interior de um meandro do rio Ingaí, partiu-se da expectativa de que as características do substrato e da comunidade arbóreo-arbustiva apresentariam variações de natureza catenária.

\section{Material e métodos}

O fragmento florestal estudado está localizado no Município de Ingaí (21⒉ $4^{\prime}$ S e $\left.44^{\circ} 55^{\prime} \mathrm{W}\right)$, região do Alto Rio Grande, sul de Minas Gerais. A floresta é conhecida localmente como Mata da Ilha e pertence à Fazenda
Cururuaçu. O nome deve-se à sua conformação, alojada no interior de um pronunciado meandro do rio Ingaí (figura 1A). A área total do fragmento é de 17 ha e sua altitude varia entre 870 e $890 \mathrm{~m}$. A Mata da Ilha é circundada por campos limpos, cerrados e áreas de cultura e, de acordo com habitantes idosos da cidade de Ingaí, o atual fragmento conectava-se com outras florestas por meio de estreitas matas ciliares, hoje removidas. Estes mesmos habitantes afirmaram ainda que nunca houve corte raso da floresta exceto em uma

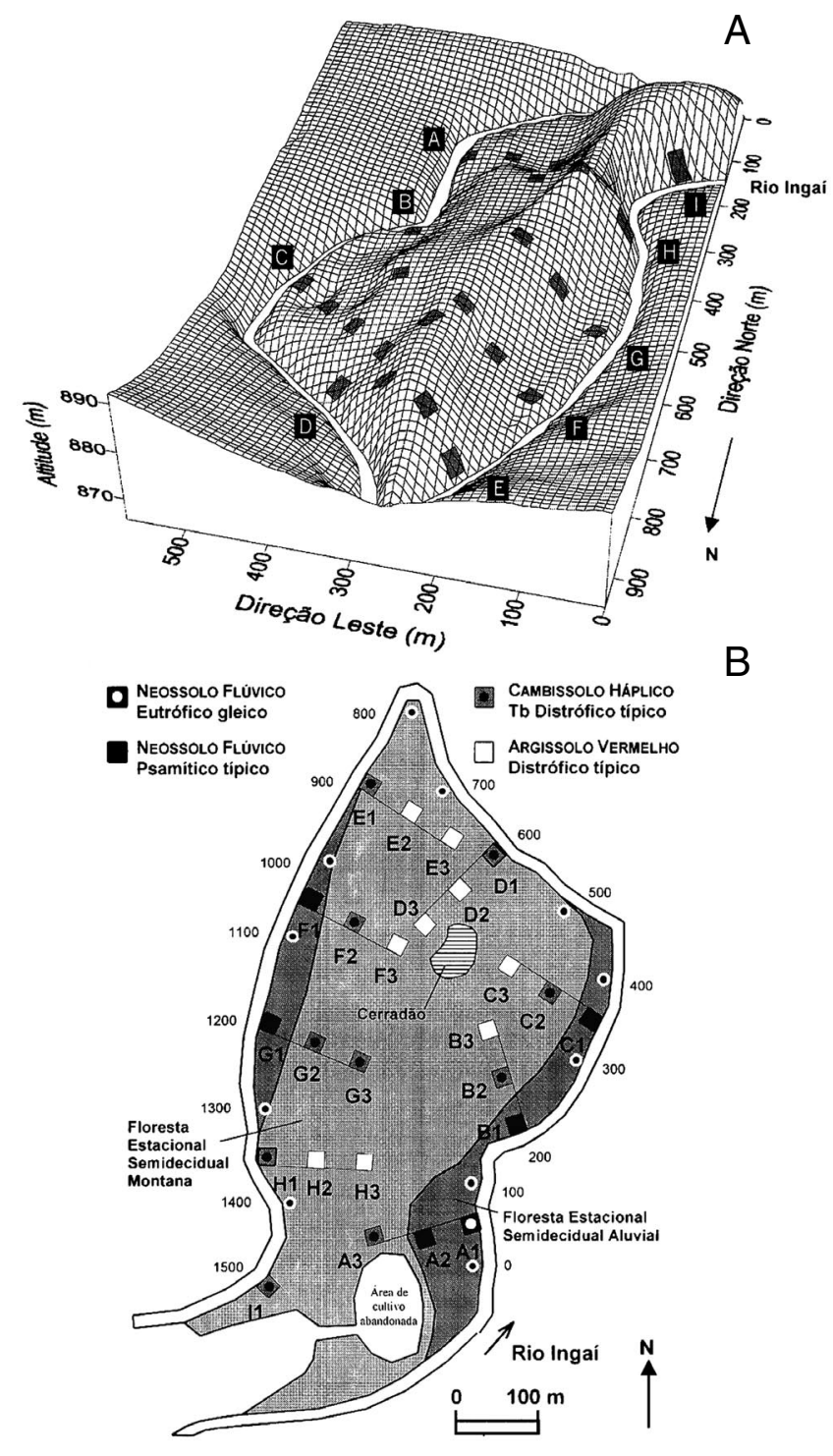

Figura 1. Mata da Ilha, Ingaí, MG: (A) Grade de superfície mostrando a topografia da área de estudos e a distribuição dos nove conglomerados amostrais (A-I). O espaçamento entre as linhas da grade é de $10 \mathrm{~m}$. (B) Mapa do fragmento florestal mostrando a distribuição parcelas amostrais de de $20 \times 20 \mathrm{~m}$, com a respectiva classificação de solos. Os números ao longo da margem do rio Ingaí marcam o caminhamento (m) utilizado para situar os conglomerados. 
pequena área ao sul que foi aberta para cultivo de feijão e depois abandonada (figura 1B) e que houve a retirada de apenas poucas árvores na borda da mata há mais de 50 anos. Desta maneira, a vegetação da maior parte da área pode ser considerada, seguramente, como em estado maduro ou de regeneração avançada.

O clima da região é do tipo Cwb de Köppen, caracterizado por verões úmidos e invernos secos (Eidt 1968), com temperatura média anual entre 19 e $20^{\circ} \mathrm{C}$ e precipitação média anual variando de 1.200 a $1.500 \mathrm{~mm}$ (Queiroz et al. 1980). A vegetação da Mata da Ilha, de acordo com a classificação do IBGE (Veloso et al. 1991), inclui três fisionomias: floresta estacional semidecidual aluvial, nos terraços adjacentes ao rio; floresta estacional semidecidual montana, predominante no interior do fragmento imediatamente acima dos terraços aluviais; e savana florestada, ou cerradão, encontrada na forma de uma pequena mancha na porção norte do fragmento (figura 1B).

O levantamento florístico da comunidade arbóreo-arbustiva da Mata da Ilha foi conduzido nas duas fisionomias florestais (cerradão excluído) por meio de coletas para identificação botânica de todas as espécies amostradas no interior das parcelas utilizadas no levantamento estrutural, bem como de outras espécies encontradas fora das parcelas em caminhadas pela mata. As visitas ocorreram entre agosto de 1999 e agosto de 2000, a intervalos que variaram de uma semana a um mês. A herborização do material botânico foi feita no Herbário do Departamento de Biologia da Universidade Federal de Lavras (Herbário ESAL) e a coleção testemunha foi incorporada ao acervo do mesmo. A identificação do material botânico foi realizada com a utilização de coleções botânicas já existentes no Herbário ESAL, e também por meio de consultas à literatura e a especialistas e a coleções dos Herbários do Jardim Botânico do Rio de Janeiro (RB), Instituto de Botânica de São Paulo (SP) e Universidade Estadual de Campinas (UEC). As espécies foram classificadas nas famílias reconhecidas pelo APG, Angiosperm Phylogeny Group (1998).

A comunidade arbóreo-arbustiva da Mata da Ilha foi amostrada em 25 parcelas de $20 \times 20 \mathrm{~m}$, dispostas em nove conglomerados (A-I), totalizando 1 ha de área amostral (figura 1). Os conglomerados foram concebidos de forma a representarem, a espaços regulares, amostras de variações presumidas para a vegetação e ambiente à medida que se afasta da margem do rio. Em cada conglomerado, foram dispostas três parcelas distantes $40 \mathrm{~m}$ uma da outra em um alinhamento perpendicular à margem do rio. $\mathrm{O}$ conglomerado A foi locado de forma arbitrária e, a partir deste, os demais foram dispostos a intervalos de $150 \mathrm{~m}$ ao longo da margem do rio, com exceção do conglomerado $\mathrm{D}$, que foi situado a distâncias superiores de seus vizinhos para evitar a interseção com os mesmos. O conglomerado I teve apenas uma parcela devido à sua proximidade da borda.

Um levantamento topográfico foi realizado da Mata da Ilha com auxílio de GPS, trena, bússola e hipsômetro de
Blume-Leiss. Com os dados deste levantamento, foi produzida uma representação tridimensional da área (figura 1A) e extraídas duas variáveis topográficas por parcela: (a) cota média, obtida da média das quatro cotas dos vértices, e (b) desnível, obtido da diferença entre as cotas máxima e mínima. Estas foram obtidas como meio de avaliação indireta das condições hidrológicas dos solos, conforme adotado por Oliveira Filho et al. (1990, 1994c).

Os solos predominantes em cada parcela foram classificados no campo de acordo com o novo Sistema Brasileiro de Classificação dos Solos (EMBRAPA 1999), chegando até o nível de subgrupo (ou 4ํㅡível categórico) e incluindo os grupamentos texturais e classes de drenagem. No centro de cada parcela, foram coletadas amostras simples do solo superficial $(0-20 \mathrm{~cm}$ de profundidade) de cerca de $500 \mathrm{ml}$. As análises químicas e texturais das amostras foram feitas no Laboratório de Análise de Solos da UFLA seguindo o protocolo da EMBRAPA (1997). As variáveis de solo obtidas foram: $\mathrm{pH}$; teores de $\mathrm{P}, \mathrm{K}, \mathrm{Ca}, \mathrm{Mg}$ e $\mathrm{Al}$; saturação por bases (valor V); matéria orgânica e teores de areia, silte e argila. As variáveis de solo foram comparadas entre três dos quatro subgrupos de solos $(N=1$ para o subgrupo não comparado) encontrados nas parcelas por meio de análises de variância seguidas de testes de Tukey onde houve diferenças significativas (Zar 1996). Variáveis expressas em proporção (p) foram transformadas previamente pela expressão arco-seno $\left(\mathrm{p}^{1 / 2}\right)$.

Em cada parcela foram registrados todos os indivíduos arbóreo-arbustivos vivos e com circunferência à altura do peito (CAP) igual ou superior a $15,7 \mathrm{~cm}$, o que equivale a um diâmetro de $5,0 \mathrm{~cm}$. Os indivíduos com caules divididos abaixo de 1,30 $\mathrm{m}$ foram incluídos no levantamento quando a área basal total dos caules correspondia a um CAP $\geq 15,7 \mathrm{~cm}$. Cada indivíduo foi marcado com etiqueta de alumínio numerada, sendo registrados seu número, a espécie, o valor do CAP, medido com fita métrica, e a altura total, estimada com auxílio de vara graduada.

A estrutura da comunidade arbóreo-arbustiva foi descrita a partir do cálculo dos parâmetros fitossociológicos descritos por Mueller-Dombois \& Ellenberg (1974) para as espécies, com adição da altura e diâmetro máximos para oferecer uma descrição do tamanho máximo alcançado pelas espécies. Os cálculos foram feitos pelo programa FITOPAC 2 (Shepherd 1994). Após verificação de normalidade pelo teste de Bartlett, a densidade e a área basal por hectare nas parcelas foram comparadas entre três subgrupos de solos (subgrupo com $N=1$ excluído) por meio de análises de variância seguidas de testes de Tukey onde houve diferenças significativas (Zar 1996). Foram preparadas distribuições de densidade de árvores por classes de diâmetro e altura para os mesmos subgrupos de solo. No caso dos diâmetros, foram empregados intervalos de classe com amplitudes crescentes para compensar o forte decréscimo da densidade nas classes de tamanho maiores, típico da distribuição em J-invertido. Estes intervalos permitem uma melhor representação das classes 
diamétricas maiores e de baixa densidade, o que é desejável em comparações gráficas (Oliveira Filho et al. 2001).

Para a determinação da diversidade de espécies foram calculados os índices de diversidade de Shannon (H') e de equabilidade de Pielou (J') em base logarítmica natural (Brower \& Zar 1984) para a amostra total e sub-amostras correspondentes aos subgrupos de solos. Os valores de H' obtidos para três sub-grupos de solos (subgrupo com $N=1$ excluído) foram comparados aos pares pelo teste de $\mathrm{t}$ de Hutcheson (Zar 1996). Para se evitar o problema causado por diferentes intensidades amostrais em comparações entre índices, foi extraída aleatoriamente uma subamostra de cinco parcelas por subgrupo de solo. Também foi extraído o número de espécies raras sensu Martins (1991), ou seja, aquelas que foram amostradas por um único indivíduo. Como a área amostral foi de 1 ha, no presente caso, o conceito coincide com de Kageyama \& Gandara (1993), que consideram raras as espécies que apresentam um indivíduo por hectare.

Para analisar as correlações entre os gradientes ambientais e vegetacionais na Mata da Ilha foi empregada a análise de correspondência canônica (CCA) (ter Braak 1987) utilizando o programa PC-ORD for Windows versão 4.14 (McCune \& Mefford 1999). A matriz de abundância das espécies foi constituída do número de indivíduos por parcela das espécies que apresentaram dez ou mais indivíduos na amostra total. De acordo com as recomendações de ter Braak (1995), os valores de abundância (a) foram transformados pela expressão $\ln (\mathrm{a}+1)$ para compensar os desvios causados por alguns poucos valores muito elevados. A parcela A1 foi removida devido à sua composição de espécies muito discrepante em relação à das demais (efeito 'outlier'). Os subgrupos de solo foram discriminados no diagrama de ordenação das parcelas para facilitar a interpretação dos padrões emergentes.

A matriz de variáveis ambientais incluiu, a princípio, todas as variáveis químicas e texturais dos solos, a classe de drenagem dos solos, a cota média e desnível máximo do terreno e a distância do rio (centro da parcela à margem). A classe de drenagem dos solos foi expressa como variável ordinal ('ranking'), da seguinte forma: 1 muito mal, 2 - mal, 3 - imperfeitamente, 4 - moderadamente, 5 - bem, e 6 - acentuadamente drenado. Após realizar uma CCA preliminar, foram eliminadas 11 variáveis ambientais fracamente correlacionadas ou altamente redundantes com outras variáveis. A CCA final foi processada com as quatro variáveis mais representativas e mais fortemente correlacionadas com os eixos de ordenação: classe de drenagem, saturação por bases, teor de $\mathrm{Al}$ e percentagem de areia. As duas variáveis com correlações mais fortes com o primeiro eixo de ordenação, a classe de drenagem e a saturação por bases, foram empregadas no cálculo de correlações de Spearman (Zar 1996) com a abundância das mesmas 48 espécies utilizadas nas análises multivariadas.

\section{Resultados}

Variáveis topográficas e edáficas - Os quatro subgrupos de solos identificados na Mata da Ilha foram representados na área amostral (figura 1B). O primeiro subgrupo foi constituído pelos Neossolos Flúvicos Tb Eutróficos gleicos, de textura média e muito mal drenados, que se localizam nos terraços aluviais mais baixos, de forma que o solo permanece saturado ou alagado por um longo período do ano. Foram amostrados em apenas uma parcela. O segundo subgrupo compreendeu os Neossolos Flúvicos Psamíticos típicos, de textura arenosa e mal drenados, que se localizam nos terraços aluviais mais altos, apenas ocasionalmente alagados. Foram amostrados em cinco parcelas. O terceiro subgrupo foi o dos Cambissolos Háplicos Tb Distróficos típicos, de textura média a argilosa e imperfeita ou moderadamente drenados, com cada classe de drenagem amostrada em cinco parcelas. Estes solos localizam-se em nível topográfico imediatamente superior ao dos terraços aluviais ou são adjacentes ao rio, onde a margem é mais declivosa, e provavelmente evoluíram a partir de depósitos aluviais mais antigos. O quarto subgrupo foi constituído pelos Argissolos Vermelhos Distróficos típicos, de textura média e bem (quatro parcelas) ou acentuadamente drenados (cinco parcelas). Tais solos distribuem-se nas áreas mais elevadas e distantes da margem do rio. Para simplificar, os quatro subgrupos de solos serão denominados, a partir daqui, de Neossolos A, Neossolos B, Cambissolos e Argissolos.

Os três subgrupos de solo com $N>1$ mostraram diferenças significativas entre si para oito das 13 variáveis topográficas e edáficas comparadas (tabela 1). A cota média do terreno foi significativamente mais elevada nos Argissolos. Os Neossolos B apresentaram teores de $\mathrm{Al}$ e matéria orgânica e proporções de argila e silte significativamente mais baixos, bem como saturação por bases e proporções de areia significativamente mais altas que os Cambissolos e Argissolos. Os teores de $\mathrm{K}$ foram significativamente mais altos nos Cambissolos e mais baixos nos Neossolos B, sendo intermediários nos Argissolos. Não houve diferenças significativas entre os três solos para desnível do terreno e para o $\mathrm{pH}$ e teores de $\mathrm{P}, \mathrm{Ca}$ e $\mathrm{Mg}$ dos solos. Apesar disso, os valores sugerem um decréscimo dos teores médios de $\mathrm{P}, \mathrm{Ca}$ e $\mathrm{Mg}$ na catena Neossolos BCambissolos-Argissolos. A única amostra dos Neossolos A destaca-se pela proporção de silte mais elevada e pelos teores relativamente altos de $\mathrm{Ca}$ e $\mathrm{Mg}$ e 
Tabela 1. Variáveis topográficas e variáveis químicas e texturais dos solos em 25 amostras do solo superficial (0-50 cm de profundidade) coletadas nas parcelas empregadas para amostrar a Mata da Ilha, Ingaí, MG. Os valores são médias \pm desvios padrão das $N$ amostras de cada um dos quatro subgrupos de solo. Onde análises de variância indicaram diferenças significativas entre três dos solos (exceto Neossolo A; $N=1$ ), as médias seguidas de letras diferentes são significativamente diferentes em testes de Tukey $(\mathrm{p}<0,05)$.

\begin{tabular}{|c|c|c|c|c|c|}
\hline & Neossolo A & Neossolo B & Cambissolo & Argissolo & ANOVA \\
\hline Variáveis & $N=1$ & $N=5$ & $N=10$ & $N=9$ & $\mathrm{~F}$ \\
\hline Cota média $^{1}(\mathrm{~m})$ & 18,1 & $19,8 \pm 0,3 b$ & $22,1 \pm 0,3 b$ & $27,2 \pm 0,3 \mathrm{a}$ & $13,5 * * *$ \\
\hline Desnível (m) & 1,0 & $2,0 \pm 0,9$ & $4,9 \pm 4,4$ & $3,3 \pm 1,2$ & $1,7 \mathrm{~ns}$ \\
\hline $\mathrm{pH}$ em $\mathrm{H}_{2} \mathrm{O}$ & 5,2 & $5,1 \pm 0,2$ & $4,9 \pm 0,2$ & $5,0 \pm 0,2$ & $0,9 \mathrm{~ns}$ \\
\hline $\mathrm{P}-$ Mehlich $\left(\mathrm{mg} \cdot \mathrm{dm}^{-3}\right)$ & 3,0 & $2,2 \pm 0,4$ & $2,0 \pm 1,5$ & $1,1 \pm 0,3$ & $2,6 \mathrm{~ns}$ \\
\hline $\mathrm{K}^{+}\left(\mathrm{mg} \cdot \mathrm{dm}^{-3}\right)$ & 41,0 & $39,0 \pm 22,0 \mathrm{~b}$ & $65,0 \pm 16,0 \mathrm{a}$ & $50,0 \pm 15,0 a b$ & $4,2 *$ \\
\hline $\mathrm{Ca}^{++}\left(\right.$cmolc. $\left.\mathrm{dm}^{-3}\right)$ & 4,2 & $1,4 \pm 1,0$ & $1,1 \pm 0,6$ & $0,5 \pm 0,2$ & $2,9 \mathrm{~ns}$ \\
\hline $\mathrm{Mg}^{++}\left(\mathrm{cmolc} \mathrm{dm}^{-3}\right)$ & 1,7 & $0,9 \pm 0,6$ & $0,8 \pm 0,7$ & $0,3 \pm 0,2$ & $3,0 \mathrm{~ns}$ \\
\hline $\mathrm{Al}^{+++}\left(\mathrm{cmolc} \cdot \mathrm{dm}^{-3}\right)$ & 0,1 & $0,4 \pm 0,2 \mathrm{~b}$ & $1,2 \pm 0,6 \mathrm{a}$ & $1,3 \pm 0,3 \mathrm{a}$ & $8,0 * *$ \\
\hline V-saturação p/bases (\%) & 57,0 & $35,0 \pm 11,0 \mathrm{a}$ & $19,0 \pm 13,0 \mathrm{~b}$ & $10,0 \pm 3,0 \mathrm{~b}$ & $9,7 * *$ \\
\hline Mat. orgânica (dag kg ${ }^{-1}$ ) & 3,3 & $1,9 \pm 1,2 b$ & $4,5 \pm 1,2 \mathrm{a}$ & $3,8 \pm 1,0 \mathrm{a}$ & $8,9 * *$ \\
\hline Areia $(\%)$ & 34,0 & $79,0 \pm 8,0 \mathrm{a}$ & $39,0 \pm 12,0 \mathrm{~b}$ & $46,0 \pm 7,0 \mathrm{~b}$ & $30,5 * * *$ \\
\hline Silte $(\%)$ & 38,0 & $8,0 \pm 6,0 \mathrm{~b}$ & $29,0 \pm 8,0 \mathrm{a}$ & $26,0 \pm 4,0 \mathrm{a}$ & $17,5 * * *$ \\
\hline Argila (\%) & 28,0 & $13,0 \pm 4,0 \mathrm{~b}$ & $33,0 \pm 7,0 \mathrm{a}$ & $28,0 \pm 6,0 \mathrm{a}$ & $17,8 * * *$ \\
\hline
\end{tabular}

${ }^{1}$ Para altitude, acrescentar $850 \mathrm{~m}$

$* \mathrm{P}<0,05, * * \mathrm{P}<0,01 ; * * * \mathrm{p}<0,001, \mathrm{~ns}=$ não significativo.

baixos de $\mathrm{Al}$, resultando em uma alta saturação por bases.

Diversidade e estrutura da comunidade arbóreoarbustiva - Foram registradas 212 espécies, 140 gêneros e 56 famílias botânicas para a Mata da Ilha (tabela 2). A família Fabaceae destacou-se pela maior riqueza de espécies (28) e gêneros (22), representando $13,7 \%$ do total de espécies registradas. A segunda maior família encontrada foi Myrtaceae, que contribuiu para a riqueza florística com 28 espécies e 10 gêneros. Outras famílias com números de espécies mais altos foram: Lauraceae (14), Euphorbiaceae (10), Rubiaceae (nove) e Asteraceae (oito). As famílias representadas por somente uma espécie somaram $20(36,4 \%)$ e aquelas contendo um só gênero foram 27 (50,9\%).

Os 2.683 indivíduos amostrados nas parcelas distribuíram-se em 140 espécies, 90 gêneros e 41 famílias botânicas. O índice de diversidade de Shannon $\left(\mathrm{H}^{\prime}\right)$ e o índice de equabilidade de Pielou (J') foram 3,734 e 0,756 , respectivamente. Alterando-se o DAP mínimo para $10 \mathrm{~cm}$, o número de espécies cai para 101 e os índices mudam para $\mathrm{H}^{\prime}=3,669$ e J' $=0,795$. Os índices de Shannon foram significativamente menores na subamostra dos Argissolos do que nas dos Cambissolos e Neossolos B (tabela 3). A menor riqueza de espécies na subamostra dos Argissolos deve ter contribuído para o fato. No entanto, a equabilidade também é bem mais baixa nestes solos, demonstrando que houve uma forte concentração de abundâncias em poucas espécies. Como ilustração, as quatro espécies mais abundantes concentraram $48 \%$ dos indivíduos. O número de espécies raras foi de 40 , o que corresponde a $1,5 \%$ dos indivíduos e $28,6 \%$ das espécies. Alterando-se o DAP mínimo para $10 \mathrm{~cm}$, o número de espécies raras cai para 30 , correspondente a $3,2 \%$ dos indivíduos e $29,7 \%$ das espécies.

Os 2.683 indivíduos com DAP $\geq 5 \mathrm{~cm}$ inventariados na amostra (1 ha) somaram uma área basal de $29,309 \mathrm{~m}^{2}$. Alterando-se o DAP mínimo para $10 \mathrm{~cm}$, estes valores mudam para 934 indivíduos e 22,460 $\mathrm{m}^{2}$. A densidade e a área basal por hectare variaram significativamente entre os três subgrupos de solo comparados (tabela 4). Os Argissolos se destacaram pela maior densidade de árvores que os Cambissolos e Neossolos B. A área basal foi significativamente maior nos Neossolos B e menor nos Argissolos, ficando os Cambissolos com valores intermediários. Tanto a densidade como a área basal foram cerca de duas a três vezes mais baixas na única parcela de Neossolo A.

As distribuições da densidade de árvores por classes de diâmetro e altura foram diferentes nos três subgrupos de solos comparados (figura 2), de acordo 
Tabela 2. Lista das espécies arbóreo-arbustivas registradas na Mata da Ilha, município de Ingaí, MG, dispostas em ordem alfabética de famílias botânicas e acompanhadas de seus respectivos números de coleta (Rg; coletora: Rejane T. Botrel) e dos parâmetros quantitativos obtidos na amostra de 25 parcelas de $20 \times 20 \mathrm{~m}$ : N. ind. = número de indivíduos nas parcelas de Neossolos (Ne), Cambissolos (Ca) e Argissolos (Ar) (+= espécie registrada fora das parcelas); $\mathrm{P}=$ número de parcelas com ocorrência da espécie; $\mathrm{AB}$ = área basal; $\mathrm{d}$ = diâmetro máximo; $\mathrm{h}$ = altura máxima e VI = valor de importância.

\begin{tabular}{|c|c|c|c|c|c|c|c|c|c|}
\hline \multirow{2}{*}{$\begin{array}{l}\text { Famílias } \\
\text { Espécies }\end{array}$} & \multirow[t]{2}{*}{$\operatorname{Rg}$} & \multicolumn{3}{|c|}{ N. ind. } & \multirow[t]{2}{*}{$\mathrm{P}$} & \multirow{2}{*}{$\begin{array}{l}\mathrm{AB} \\
\left(\mathrm{m}^{2}\right)\end{array}$} & \multirow{2}{*}{$\begin{array}{c}\mathrm{d} \\
(\mathrm{cm})\end{array}$} & \multirow{2}{*}{$\begin{array}{l}\mathrm{h} \\
(\mathrm{m})\end{array}$} & \multirow[t]{2}{*}{ VI } \\
\hline & & $\mathrm{Ne}$ & $\mathrm{Ca}$ & $\mathrm{Ar}$ & & & & & \\
\hline \multicolumn{10}{|l|}{ ANACARDIACEAE } \\
\hline Lithraea molleoides (Vell.) Engler & 1 & 26 & 25 & 9 & 16 & 0,913 & 32,8 & 13,0 & 7,41 \\
\hline Schinus terebinthifolius Raddi & 4 & - & - & + & - & - & - & - & - \\
\hline Tapirira guianensis Aublet & 2 & 30 & 84 & 57 & 23 & 1,963 & 33,4 & 14,0 & 16,04 \\
\hline Tapirira obtusa (Benth.) Mitchell & 3 & 25 & 46 & 55 & 23 & 1,701 & 32,4 & 13,0 & 13,46 \\
\hline \multicolumn{10}{|l|}{ ANNONACEAE } \\
\hline Annona crassiflora Mart. & 5 & - & - & + & - & - & - & - & - \\
\hline Guatteria nigrescens Mart. & 6 & - & 2 & 6 & 4 & 0,027 & 8,1 & 8,5 & 0,90 \\
\hline Rollinia emarginata Schltdl. & 7 & 3 & 9 & - & 5 & 0,045 & 8,9 & 8,5 & 1,24 \\
\hline Rollinia laurifolia Schltdl. & 8 & 2 & 5 & + & 5 & 0,078 & 19,4 & 13,0 & 1,17 \\
\hline Rollinia sericea (R.E. Fries) R.E. Fries & 9 & 1 & + & + & 1 & 0,003 & 6,4 & 7,0 & 0,18 \\
\hline Rollinia sylvatica (A. St.-Hil.) Mart. & 10 & - & 1 & + & 1 & 0,004 & 6,8 & 5,5 & 0,18 \\
\hline Xylopia brasiliensis Sprengel & 11 & - & + & - & - & - & - & - & - \\
\hline \multicolumn{10}{|l|}{ APOCYNACEAE } \\
\hline Aspidosperma cylindrocarpon Müll. Arg. & 12 & - & 2 & 2 & 3 & 0,026 & 9,9 & 9,5 & 0,63 \\
\hline Aspidosperma parvifolium A. DC. & 13 & - & + & + & - & - & - & - & - \\
\hline Aspidosperma ramiflorum Müll. Arg. & 14 & - & - & + & - & - & - & - & - \\
\hline Aspidosperma spruceanum Benth. & 15 & - & + & - & - & - & - & - & - \\
\hline \multicolumn{10}{|l|}{ AQUIFOLIACEAE } \\
\hline Ilex cerasifolia Reissek & 16 & - & + & + & - & - & - & - & - \\
\hline Ilex conocarpa Reissek & 17 & - & + & + & - & - & - & - & - \\
\hline \multicolumn{10}{|l|}{ ARALIACEAE } \\
\hline Dendropanax affinis (E. Marchal) & 216 & - & - & + & - & - & - & - & - \\
\hline \multicolumn{10}{|c|}{ Gamerro \& Zuloaga } \\
\hline Dendropanax cuneatus (DC.) Decne \& Planchon & 18 & 22 & 22 & 4 & 17 & 0,258 & 19,0 & 11,0 & 4,86 \\
\hline Schefflera macrocarpa (Cham. \& Schltdl.) D. Frodin & n 19 & - & - & + & - & - & - & - & - \\
\hline \multicolumn{10}{|l|}{ ARECACEAE } \\
\hline Syagrus romanzoffiana (Cham.) Glassman & 20 & + & + & - & - & - & - & - & - \\
\hline \multicolumn{10}{|l|}{ ASTERACEAE } \\
\hline Dasyphyllum brasiliense (Sprengel) Cabrera & 21 & - & + & + & - & - & - & - & - \\
\hline Eremanthus erythropappus (DC.) MacLeish & 209 & - & - & + & - & - & - & - & - \\
\hline Eremanthus incanus (Less.) Less. & 22 & - & - & 1 & 1 & 0,025 & 17,8 & 12,0 & 0,25 \\
\hline Eupatorium vauthierianum DC. & 210 & - & 1 & - & 1 & 0,003 & 6,3 & 7,0 & 0,18 \\
\hline Gochnatia paniculata (Less.) Cabrera & 23 & - & - & 9 & 4 & 0,083 & 16,2 & 7,5 & 1,13 \\
\hline Piptocarpha macropoda Baker & 24 & - & - & 1 & 1 & 0,021 & 16,2 & 13,0 & 0,24 \\
\hline Vernonanthura diffusa (Less.) H. Robinson & 25 & - & 5 & 1 & 3 & 0,265 & 35,5 & 13,0 & 1,51 \\
\hline Vernonanthura phosphorica (Vell.) H. Robinson & 26 & - & - & + & - & - & - & - & - \\
\hline \multicolumn{10}{|l|}{ BIGNONIACEAE } \\
\hline Cybistax antisyphillitica Mart. & 29 & - & + & + & - & - & - & - & - \\
\hline Tabebuia chrysotricha (Mart.) Standley & 30 & - & - & 4 & 3 & 0,020 & 10,2 & 6,0 & 0,60 \\
\hline Tabebuia ochracea (Cham.) Rizz. & 31 & - & - & + & - & - & - & - & - \\
\hline Tabebuia serratifolia (Vahl) Nichols & 32 & 5 & 11 & 6 & 13 & 0,230 & 23,1 & 11,0 & 3,28 \\
\hline \multicolumn{10}{|l|}{ BORAGINACEAE } \\
\hline Cordia sellowiana Cham. & 34 & - & + & + & - & - & - & - & - \\
\hline Cordia trichotoma (Vell.) Arrab. & 33 & 13 & 1 & - & 2 & 0,075 & 15,1 & 10,0 & 1,04 \\
\hline \multicolumn{10}{|l|}{ BURSERACEAE } \\
\hline Protium heptaphyllum (Aublet) Marchand & 35 & 1 & 5 & + & 3 & 0,067 & 17,2 & 11,0 & 0,84 \\
\hline Protium spruceanum (Benth.) Engler & 36 & + & 2 & 1 & 2 & 0,028 & 13,4 & 10,0 & 0,46 \\
\hline Protium widgrenii Engler & 37 & 2 & 40 & 24 & 19 & 0,414 & 19,9 & 11,0 & 6,32 \\
\hline
\end{tabular}


Tabela 2 (cont.)

\begin{tabular}{|c|c|c|c|c|c|c|c|c|c|}
\hline \multirow{2}{*}{$\begin{array}{l}\text { Famílias } \\
\text { Espécies }\end{array}$} & \multirow[t]{2}{*}{$\operatorname{Rg}$} & \multicolumn{3}{|c|}{ N. ind. } & \multirow[t]{2}{*}{$\mathrm{P}$} & \multirow{2}{*}{$\begin{array}{l}\mathrm{AB} \\
\left(\mathrm{m}^{2}\right)\end{array}$} & \multirow{2}{*}{$\begin{array}{c}\mathrm{d} \\
(\mathrm{cm})\end{array}$} & \multirow{2}{*}{$\begin{array}{c}\mathrm{h} \\
(\mathrm{m})\end{array}$} & \multirow[t]{2}{*}{ VI } \\
\hline & & $\mathrm{Ne}$ & $\mathrm{Ca}$ & Ar & & & & & \\
\hline \multicolumn{10}{|l|}{ CARYOCARACEAE } \\
\hline Caryocar brasiliense Cambess. & 38 & - & - & + & - & - & - & - & - \\
\hline \multicolumn{10}{|l|}{ CECROPIACEAE } \\
\hline Cecropia pachystachya Trécul & 39 & + & - & - & - & - & - & - & - \\
\hline \multicolumn{10}{|l|}{ CELASTRACEAE } \\
\hline Austroplenckia populnea (Reissek) Lundell & 40 & - & 1 & + & 1 & 0,007 & 9,2 & 9,0 & 0,19 \\
\hline Maytenus glazioviana Loesen & 42 & - & 1 & 2 & 3 & 0,018 & 12,7 & 9,0 & 0,56 \\
\hline Maytenus ilicifolia Mart. & 41 & - & + & - & - & - & - & - & - \\
\hline Maytenus salicifolia Reissek & 43 & 1 & 2 & 5 & 7 & 0,071 & 21,8 & 10,0 & 1,44 \\
\hline \multicolumn{10}{|l|}{ CELTIDACEAE } \\
\hline Celtis iguanaea (Jacquin) Sargent & 44 & - & + & + & - & - & - & - & - \\
\hline \multicolumn{10}{|l|}{ CLETHRACEAE } \\
\hline Clethra scabra Pers. & 45 & - & 1 & 7 & 3 & 0,038 & 9,4 & 7,0 & 0,81 \\
\hline \multicolumn{10}{|l|}{ CLUSIACEAE } \\
\hline Calophyllum brasiliense Cambess. & 48 & + & - & - & - & - & - & - & - \\
\hline Vismia brasiliensis Choisy & 47 & 2 & - & 3 & 4 & 0,040 & 17,4 & 11,0 & 0,84 \\
\hline \multicolumn{10}{|l|}{ COMBRETACEAE } \\
\hline Terminalia glabrescens Mart. & 46 & - & + & + & - & - & - & - & - \\
\hline \multicolumn{10}{|l|}{ CONNARACEAE } \\
\hline Connarus regnellii $\mathrm{G}$. Schelenb. & 49 & - & 1 & + & 1 & 0,004 & 7,3 & 7,0 & 0,18 \\
\hline CUNONIACEAE & & & & & & & & & \\
\hline Lamanonia ternata Vell. & 50 & - & 7 & 34 & 11 & 0,596 & 45,5 & 11,0 & 4,98 \\
\hline EBENACEAE & & & & & & & & & \\
\hline Diospyros hispida A. DC. & 52 & - & + & + & - & - & - & - & - \\
\hline Diospyros inconstans Jacquin & 51 & 2 & 3 & - & 4 & 0,038 & 13,1 & 11,0 & 0,83 \\
\hline ERYTHROXYLACEAE & & & & & & & & & \\
\hline Erythroxylum deciduum A. St.-Hil. & 211 & 1 & + & + & 1 & 0,012 & 12,4 & 10,0 & 0,21 \\
\hline Erythroxylum pelleterianum A. St.-Hil. & 53 & - & 4 & + & 3 & 0,024 & 12,1 & 10,0 & 0,62 \\
\hline EUPHORBIACEAE & & & & & & & & & \\
\hline Actinostemon concolor (Sprengel) Müll. Arg. & 54 & 16 & 10 & - & 6 & 0,230 & 20,4 & 12,0 & 2,53 \\
\hline Alchornea glandulosa Poepp. \& Endl. & 55 & - & - & + & - & - & - & - & - \\
\hline Croton floribundus Sprengel & 56 & - & + & + & - & - & - & - & - \\
\hline Croton urucurana Baillon & 57 & 16 & - & - & 1 & 0,389 & 30,6 & 14,0 & 2,05 \\
\hline Hyeronima ferruginea Müll. Arg. & 58 & + & - & - & - & - & - & - & - \\
\hline Pera glabrata (Schott.) Poepp. & 59 & 1 & 1 & 1 & 3 & 0,011 & 7,5 & 11,0 & 0,54 \\
\hline Sapium glandulosum (L.) Morong & 60 & - & + & - & - & - & - & - & - \\
\hline Sebastiania brasiliensis Sprengel & 61 & 13 & 5 & 3 & 10 & 0,148 & 18,8 & 10,0 & 2,57 \\
\hline Sebastiania commersoniana (Baillon) & 62 & 16 & 2 & - & 3 & 0,304 & 31,2 & 13,0 & 2,09 \\
\hline Smith \& Downs & & & & & & & & & \\
\hline Sebastiania schottiana (Müll. Arg.) Müll. Arg. & 63 & 1 & - & - & 1 & 0,016 & 14,2 & 3,5 & 0,22 \\
\hline FABACEAE & & & & & & & & & \\
\hline Acacia glomerosa Benth. & 83 & + & + & - & - & - & - & - & - \\
\hline Albizia polycephala (Benth.) Killip & 84 & 1 & 1 & 1 & 3 & 0,022 & 14,6 & 14,0 & 0,57 \\
\hline Andira fraxinifolia Benth. & 71 & 9 & 17 & 9 & 17 & 0,295 & 24,1 & 10,0 & 4,50 \\
\hline Bauhinia longifolia (Bongard) Steudel & 64 & 15 & 1 & 1 & 3 & 0,110 & 17,3 & 9,5 & 1,40 \\
\hline Bowdichia virgilioides Kunth & 72 & - & + & + & - & - & - & - & - \\
\hline Cassia ferruginea (Schrad.) Schrad. & 65 & 5 & - & - & 3 & 0,368 & 56,1 & 15,0 & 1,83 \\
\hline Copaifera langsdorffii Desf. & 66 & 13 & 116 & 302 & 23 & 5,784 & 47,8 & 16,0 & 38,76 \\
\hline Dalbergia miscolobium Benth. & 73 & - & - & 1 & 1 & 0,008 & 10,2 & 6,5 & 0,19 \\
\hline Dalbergia villosa (Benth.) Benth. & 74 & 1 & 5 & 1 & 4 & 0,058 & 18,3 & 11,0 & 0,97 \\
\hline Enterolobium gummiferum (Mart.) Macbr. & 85 & - & - & + & - & - & - & - & - \\
\hline Erythrina falcata Benth. & 75 & 1 & - & - & 1 & 0,142 & 42,4 & 15,0 & 0,65 \\
\hline Hymenaea courbaril L. & 67 & - & 1 & - & 1 & 0,046 & 24,2 & 9,5 & 0,32 \\
\hline Inga striata Benth. & 86 & 1 & 1 & - & 2 & 0,007 & 7,8 & 10,0 & 0,36 \\
\hline
\end{tabular}


Tabela 2 (cont.)

\begin{tabular}{|c|c|c|c|c|c|c|c|c|c|}
\hline \multirow{2}{*}{$\begin{array}{l}\text { Famílias } \\
\text { Espécies }\end{array}$} & \multirow[t]{2}{*}{$\operatorname{Rg}$} & \multicolumn{3}{|c|}{ N. ind. } & \multirow[t]{2}{*}{$\mathrm{P}$} & \multirow{2}{*}{$\begin{array}{l}\mathrm{AB} \\
\left(\mathrm{m}^{2}\right)\end{array}$} & \multirow{2}{*}{$\begin{array}{c}\mathrm{d} \\
(\mathrm{cm})\end{array}$} & \multirow{2}{*}{$\begin{array}{l}\mathrm{h} \\
(\mathrm{m})\end{array}$} & \multirow[t]{2}{*}{ VI } \\
\hline & & $\mathrm{Ne}$ & $\mathrm{Ca}$ & $\mathrm{Ar}$ & & & & & \\
\hline \multicolumn{10}{|l|}{ FABACEAE } \\
\hline Inga vera Willd. & 87 & 4 & 2 & - & 2 & 0,190 & 40,3 & 13,0 & 1,13 \\
\hline Leucochloron incuriale (Vell.) Barneby \& Grimes & 88 & - & + & + & - & - & - & - & - \\
\hline Lonchocarpus cultratus (Vell.) Az. Tozzi \& H. Lima & a 76 & 1 & 1 & + & 2 & 0,156 & 44,3 & 16,0 & 0,86 \\
\hline Machaerium hirtum (Vell.) Stellfeld & 77 & 8 & 6 & 3 & 12 & 0,194 & 23,5 & 13,0 & 2,84 \\
\hline Machaerium nictitans (Vell.) Benth. & 78 & 7 & 9 & 1 & 9 & 0,470 & 38,9 & 14,0 & 3,40 \\
\hline Machaerium stipitatum (DC.) Vogel & 79 & 12 & 3 & + & 7 & 0,109 & 14,6 & 17,0 & 1,83 \\
\hline Machaerium villosum Vogel & 80 & 4 & 40 & 21 & 19 & 2,040 & 56,3 & 15,0 & 11,83 \\
\hline Mimosa scabrela Benth. & 90 & - & - & + & - & - & - & - & - \\
\hline Piptadenia gonoacantha (Mart.) Macbr. & 91 & - & + & + & - & - & - & - & - \\
\hline Platycyamus regnellii Benth. & 81 & - & 1 & + & 1 & 0,034 & 20,9 & 12,5 & 0,28 \\
\hline Platypodium elegans Vogel & 82 & 2 & 17 & 48 & 16 & 0,617 & 31,0 & 13,0 & 6,66 \\
\hline Sclerolobium rugosum Mart. & 70 & - & + & - & - & - & - & - & - \\
\hline Senna macranthera (Vell.) Irwin \& Barneby & 68 & - & 1 & + & 1 & 0,004 & 7,5 & 10,0 & 0,18 \\
\hline Senna multijuga (L.C. Rich.) Irwin \& Barneby & 69 & - & 1 & + & 1 & 0,003 & 6,4 & 8,0 & 0,18 \\
\hline Stryphnodendron adstringens (Mart.) Cov. & 92 & - & - & + & - & - & - & - & - \\
\hline \multicolumn{10}{|l|}{ FLACOURTIACEAE } \\
\hline Casearia decandra Jacquin & 93 & 1 & 6 & 12 & 11 & 0,126 & 12,9 & 10,5 & 2,55 \\
\hline Casearia lasiophylla Eichler & 94 & - & 4 & + & 3 & 0,019 & 9,6 & 10,0 & 0,60 \\
\hline Casearia obliqua Sprengel & 95 & - & 1 & + & 1 & 0,646 & 90,7 & 14,0 & 2,37 \\
\hline Casearia sylvestris Swartz & 96 & 58 & 24 & + & 16 & 0,471 & 17,5 & 11,0 & 6,72 \\
\hline Xylosma ciliatifolium (Clos) Eichler & 97 & 4 & 4 & 5 & 7 & 0,126 & 19,9 & 12,0 & 1,81 \\
\hline \multicolumn{10}{|l|}{ LAURACEAE } \\
\hline Aiouea costaricensis (Mez) Kosterm. & 110 & - & 1 & - & 1 & 0,047 & 24,4 & 9,5 & 0,33 \\
\hline Aniba firmula (Nees \& Mart.) Mez & 98 & - & + & - & - & - & - & - & - \\
\hline Cryptocarya aschersoniana $\mathrm{Mez}$ & 99 & 2 & 2 & - & 4 & 0,100 & 23,2 & 11,0 & 1,00 \\
\hline Endlicheria paniculata (Sprengel) Macbr. & 100 & + & - & - & - & - & - & - & - \\
\hline Nectandra grandiflora Nees & 101 & 2 & 1 & - & 2 & 0,037 & 17,9 & 7,0 & 0,50 \\
\hline Nectandra megapotamica (Sprengel) Mez & 103 & 16 & 3 & - & 9 & 0,212 & 20,7 & 11,0 & 2,59 \\
\hline Nectandra nitidula Nees & 104 & 10 & 29 & 5 & 14 & 0,370 & 23,5 & 11,0 & 4,71 \\
\hline Nectandra oppositifolia Nees & 105 & - & + & + & - & - & - & - & - \\
\hline Nectandra puberula (Schott) Nees & 102 & - & + & - & - & - & - & - & - \\
\hline Ocotea corymbosa (Meisner) Mez & 106 & - & + & 1 & 1 & 0,005 & 8,3 & 7,5 & 0,18 \\
\hline Ocotea odorifera (Vell.) Rohwer & 107 & - & + & - & - & - & - & - & - \\
\hline Ocotea pulchella Mart. & 108 & 1 & 7 & 8 & 11 & 0,053 & 12,6 & 9,0 & 2,19 \\
\hline Ocotea variabilis (Nees) Mez & 109 & 1 & - & - & 1 & 0,015 & 13,7 & 10,0 & 0,22 \\
\hline Persea pyrifolia Nees \& Mart. & 111 & - & 1 & + & 1 & 0,010 & 11,1 & 12,0 & 0,20 \\
\hline \multicolumn{10}{|l|}{ LOGANIACEAE } \\
\hline Strychnos brasiliensis (Sprengel) Mart. & 112 & 2 & 6 & - & 5 & 0,048 & 15,5 & 7,5 & 1,11 \\
\hline \multicolumn{10}{|l|}{ LYTHRACEAE } \\
\hline Lafoensia densiflora Pohl & 206 & - & + & + & - & - & - & - & - \\
\hline Lafoensia pacari A. St.-Hil. & 113 & 1 & 8 & 8 & 8 & 0,393 & 33,5 & 11,0 & 3,00 \\
\hline \multicolumn{10}{|l|}{ MAGNOLIACEAE } \\
\hline Talauma ovata A. St.-Hil. & 114 & + & - & - & - & - & - & - & - \\
\hline \multicolumn{10}{|l|}{ MALPIGHIACEAE } \\
\hline Byrsonima laxiflora Griseb. & 115 & - & - & 1 & 1 & 0,007 & 9,2 & 7,5 & 0,19 \\
\hline Heteropterys byrsonimifolia A. Juss. & 116 & - & - & 6 & 2 & 0,079 & 23,9 & 13,0 & 0,75 \\
\hline \multicolumn{10}{|l|}{ MALVACEAE } \\
\hline Eriotheca candolleana (K. Schum.) A. Robyns & 117 & - & 1 & + & 1 & 0,039 & 22,3 & 15,0 & 0,30 \\
\hline Helicteres ovata Lam. & 118 & - & 1 & - & 1 & 0,004 & 6,7 & 7,0 & 0,18 \\
\hline Luehea candicans Mart. & 119 & 1 & - & - & 1 & 0,023 & 17,2 & 10,0 & 0,25 \\
\hline Luehea divaricata Mart. \& Zucc. & 120 & 17 & 9 & - & 11 & 0,986 & 41,5 & 16,0 & 5,75 \\
\hline Luehea grandiflora Mart. \& Zucc. & 121 & - & 13 & 7 & 7 & 0,175 & 18,3 & 11,0 & 2,24 \\
\hline MELASTOMATACEAE & & & & & & & & & \\
\hline Leandra scabra DC. & 122 & - & 1 & + & 1 & 0,003 & 5,7 & 4,0 & 0,17 \\
\hline
\end{tabular}


Tabela 2 (cont.)

\begin{tabular}{|c|c|c|c|c|c|c|c|c|c|}
\hline \multirow{2}{*}{$\begin{array}{l}\text { Famílias } \\
\text { Espécies }\end{array}$} & \multirow[t]{2}{*}{$\operatorname{Rg}$} & \multicolumn{3}{|c|}{ N. ind. } & \multirow[t]{2}{*}{$\mathrm{P}$} & \multirow{2}{*}{$\begin{array}{l}\mathrm{AB} \\
\left(\mathrm{m}^{2}\right)\end{array}$} & \multirow{2}{*}{$\begin{array}{c}\mathrm{d} \\
(\mathrm{cm})\end{array}$} & \multirow{2}{*}{$\begin{array}{l}\mathrm{h} \\
(\mathrm{m})\end{array}$} & \multirow[t]{2}{*}{ VI } \\
\hline & & $\mathrm{Ne}$ & $\mathrm{Ca}$ & $\mathrm{Ar}$ & & & & & \\
\hline \multicolumn{10}{|l|}{ MELASTOMATACEAE } \\
\hline Miconia argyrophylla DC. & 123 & - & 1 & + & 1 & 0,002 & 5,6 & 7,5 & 0,17 \\
\hline Miconia pepericarpa DC. & 124 & - & - & + & - & - & - & - & - \\
\hline Tibouchina candolleana (DC.) Cogn. & 125 & - & - & + & - & - & - & - & - \\
\hline \multicolumn{10}{|l|}{ MELIACEAE } \\
\hline Cabralea canjerana (Vell.) Mart. & 126 & - & + & + & - & - & - & - & - \\
\hline Cedrela fissilis Vell. & 127 & - & 1 & - & 1 & 0,009 & 10,5 & 8,0 & 0,20 \\
\hline Guarea kunthiana A. Juss. & 128 & + & - & - & - & - & - & - & - \\
\hline Trichilia emarginata (Turcz.) C. DC. & 129 & - & + & - & - & - & - & - & - \\
\hline Trichilia pallida Swartz & 130 & - & + & + & - & - & - & - & - \\
\hline \multicolumn{10}{|l|}{ MONIMIACEAE } \\
\hline Mollinedia widgrenii A. DC. & 131 & - & + & + & - & - & - & - & - \\
\hline \multicolumn{10}{|l|}{ MORACEAE } \\
\hline Brosimum gaudichaudii Trécul & 132 & - & - & + & - & - & - & - & - \\
\hline Ficus mexiae Standley & 133 & - & 1 & - & 1 & 0,065 & 28,7 & 13,0 & 0,39 \\
\hline Maclura tinctoria (L.) D. Don. & 134 & - & - & + & - & - & - & - & - \\
\hline Sorocea bonplandii (Baillon) W. Burger & 135 & 1 & + & - & 1 & 0,035 & 21,1 & 7,5 & 0,29 \\
\hline \multicolumn{10}{|l|}{ MYRSINACEAE } \\
\hline Myrsine coriacea (Swartz) R. Br. & 136 & 1 & - & 1 & 2 & 0,062 & 27,5 & 13,0 & 0,54 \\
\hline Myrsine guianensis (Aublet) Kuntze & 137 & - & - & + & - & - & - & - & - \\
\hline Myrsine lancifolia Mart. & 138 & - & 1 & 1 & 2 & 0,004 & 5,3 & 10,0 & 0,35 \\
\hline Myrsine umbellata Mart. & 139 & 14 & 55 & 186 & 21 & 1,431 & 22,8 & 12,0 & 17,09 \\
\hline \multicolumn{10}{|l|}{ MYRTACEAE } \\
\hline Blepharocalyx salicifolius (Kunth) O. Berg & 140 & - & 1 & 1 & 2 & 0,062 & 27,6 & 11,0 & 0,54 \\
\hline Calyptranthes brasiliensis Sprengel & 141 & - & 1 & + & 1 & 0,002 & 5,3 & 7,0 & 0,17 \\
\hline Calyptranthes clusiifolia (Miq.) O. Berg & 142 & - & + & + & - & - & - & - & - \\
\hline Campomanesia guazumifolia (Cambess.) O. Berg & 143 & 8 & 3 & - & 6 & 0,088 & 18,9 & 10,0 & 1,48 \\
\hline Campomanesia pubescens (DC.) O. Berg & 144 & - & - & + & - & - & - & - & - \\
\hline Campomanesia simulans M.L. Kawasaki & 145 & 3 & - & - & 1 & 0,034 & 15,7 & 9,5 & 0,36 \\
\hline Campomanesia velutina (Cambess.) O. Berg & 146 & 2 & + & 8 & 4 & 0,048 & 11,8 & 7,0 & 1,05 \\
\hline Campomanesia xanthocarpa O. Berg & 147 & - & 1 & 1 & 2 & 0,006 & 6,2 & 8,0 & 0,35 \\
\hline Eugenia florida DC. & 148 & 5 & 20 & 2 & 6 & 0,291 & 21,8 & 12,0 & 2,77 \\
\hline Eugenia hyemalis Cambess. & 149 & - & 1 & + & 1 & 0,008 & 9,9 & 8,0 & 0,19 \\
\hline Eugenia pluriflora DC. & 152 & - & 1 & 1 & 2 & 0,007 & 7,5 & 10,0 & 0,35 \\
\hline Eugenia punicifolia (Kunth) DC. & 150 & - & - & 4 & 3 & 0,016 & 9,0 & 9,0 & 0,59 \\
\hline Eugenia uniflora $\mathrm{L}$. & 213 & 2 & 1 & - & 2 & 0,036 & 18,3 & 8,0 & 0,49 \\
\hline Gomidesia affinis (Cambess.) D. Legrand & 153 & 8 & 12 & 1 & 9 & 0,117 & 12,8 & 12,0 & 2,34 \\
\hline Gomidesia eriocalyx (DC.) O. Berg & 154 & 2 & 1 & - & 2 & 0,017 & 12,3 & 12,0 & 0,43 \\
\hline Myrcia fallax (Rich.) DC. & 155 & 1 & 2 & 6 & 4 & 0,044 & 9,6 & 13,0 & 1,00 \\
\hline Myrcia laruotteana Cambess. & 156 & - & 1 & + & 1 & 0,005 & 7,5 & 7,0 & 0,18 \\
\hline Myrcia multiflora (Lam.) DC. & 157 & 11 & 11 & 22 & 17 & 0,303 & 27,5 & 10,0 & 4,87 \\
\hline Myrcia rostrata $\mathrm{DC}$ & 158 & 5 & 11 & 23 & 18 & 0,181 & 12,7 & 10,0 & 4,39 \\
\hline Myrcia tomentosa (Aublet) DC. & 159 & 2 & 10 & 42 & 14 & 0,450 & 19,5 & 10,0 & 5,35 \\
\hline Myrcia venulosa DC. & 160 & 5 & 36 & 18 & 19 & 0,384 & 26,9 & 12,0 & 5,96 \\
\hline Myrciaria tenella (DC.) O. Berg & 161 & - & + & + & - & - & - & - & - \\
\hline Pimenta pseudocaryophyllus (Gomes) Landrum & 162 & - & - & + & - & - & - & - & - \\
\hline Psidium cattleyanum Sabine & 163 & - & - & 1 & 1 & 0,002 & 5,3 & 7,5 & 0,17 \\
\hline Psidium guajava $\mathrm{L}$. & 164 & - & - & + & - & - & - & - & - \\
\hline Psidium rufum Mart. & 165 & - & 1 & 1 & 2 & 0,010 & 8,4 & 7,5 & 0,37 \\
\hline Siphoneugena densiflora O. Berg & 166 & - & 6 & 4 & 7 & 0,084 & 14,0 & 9,5 & 1,56 \\
\hline Siphoneugena widgreniana O. Berg & 167 & - & - & + & - & - & - & - & - \\
\hline \multicolumn{10}{|l|}{ NYCTAGINACEAE } \\
\hline Guapira hirsuta (Choisy) Lundell & 168 & - & - & 3 & 3 & 0,016 & 8,8 & 7,0 & 0,55 \\
\hline Guapira opposita (Vell.) Reitz & 169 & - & 2 & 4 & 5 & 0,020 & 7,6 & 7,0 & 0,94 \\
\hline
\end{tabular}


Tabela 2 (cont.)

\begin{tabular}{|c|c|c|c|c|c|c|c|c|c|}
\hline \multirow{2}{*}{$\begin{array}{l}\text { Famílias } \\
\text { Espécies }\end{array}$} & \multirow[t]{2}{*}{$\operatorname{Rg}$} & \multicolumn{3}{|c|}{ N. ind. } & \multirow[t]{2}{*}{$\mathrm{P}$} & \multirow{2}{*}{$\begin{array}{l}\mathrm{AB} \\
\left(\mathrm{m}^{2}\right)\end{array}$} & \multirow{2}{*}{$\begin{array}{c}\mathrm{d} \\
(\mathrm{cm})\end{array}$} & \multirow{2}{*}{$\begin{array}{l}\mathrm{h} \\
(\mathrm{m})\end{array}$} & \multirow[t]{2}{*}{ VI } \\
\hline & & $\mathrm{Ne}$ & $\mathrm{Ca}$ & $\mathrm{Ar}$ & & & & & \\
\hline \multicolumn{10}{|l|}{ PICRAMNIACEAE } \\
\hline Picramnia ciliata Mart. & 170 & - & + & - & - & - & - & - & - \\
\hline \multicolumn{10}{|l|}{ POLYGONACEAE } \\
\hline Coccoloba mollis Casar. & 214 & - & - & + & - & - & - & - & - \\
\hline \multicolumn{10}{|l|}{ PROTEACEAE } \\
\hline Euplassa incana (Klotzsch) Johnston & 172 & - & - & + & - & - & - & - & - \\
\hline Roupala montana Aublet & 171 & 1 & 3 & + & 4 & 0,159 & 30,6 & 15,0 & 1,21 \\
\hline \multicolumn{10}{|l|}{ RHAMNACEAE } \\
\hline Rhamnus sphaerosperma Swartz & 173 & - & - & 1 & 1 & 0,003 & 6,1 & 7,5 & 0,18 \\
\hline \multicolumn{10}{|l|}{ ROSACEAE } \\
\hline \multicolumn{3}{|l|}{ RUBIACEAE } & & 2 & 8 & 0,085 & 15,2 & 11,0 & 1,77 \\
\hline Amaioua guianensis Aublet & 176 & - & 6 & 1 & 3 & 0,023 & 8,9 & 7,5 & 0,73 \\
\hline Chomelia sericeas Müll. Arg. & 178 & 7 & 9 & - & 10 & 0,091 & 15,3 & 8,5 & 2,20 \\
\hline Faramea cyanea Müll. Arg. & 177 & 2 & 1 & 2 & 4 & 0,037 & 14,0 & 8,0 & 0,83 \\
\hline Guettarda viburnoides Cham. \& Schltdl. & 179 & - & 2 & 8 & 4 & 0,033 & 9,7 & 8,5 & 1,00 \\
\hline Ixora warmingii Müll. Arg. & 180 & - & 4 & 1 & 3 & 0,027 & 11,3 & 7,0 & 0,67 \\
\hline Psychotria deflexa DC. & 181 & - & + & - & - & - & - & - & - \\
\hline Randia nitida (Kunth) DC. & 182 & 2 & 4 & - & 4 & 0,033 & 10,8 & 9,0 & 0,85 \\
\hline Rudgea viburnoides (Cham.) Benth. & 183 & - & - & + & - & - & - & - & - \\
\hline Simira sampairana (Standley) Steyerm. & 175 & 3 & 20 & 33 & 16 & 0,301 & 17,5 & 10,0 & 5,18 \\
\hline \multicolumn{10}{|l|}{ RUTACEAE } \\
\hline Galipea jasminiflora (A. St.-Hil.) Engler & 184 & - & + & + & - & - & - & - & - \\
\hline Metrodorea stipularis Mart. & 185 & 1 & 2 & - & 2 & 0,057 & 17,1 & 11,0 & 0,56 \\
\hline Zanthoxylum rhoifolium Lam. & 186 & - & 1 & + & 1 & 0,004 & 7,0 & 9,5 & 0,18 \\
\hline \multicolumn{10}{|l|}{ SALICACEAE } \\
\hline Salix humboldtiana Willd. & 212 & + & - & - & - & - & - & - & - \\
\hline \multicolumn{10}{|l|}{ SAPINDACEAE } \\
\hline Cupania vernalis Cambess. & 187 & 9 & 43 & 9 & 17 & 0,305 & 15,0 & 14,0 & 5,51 \\
\hline Matayba elaeagnoides Radlk. & 188 & 15 & 37 & 47 & 23 & 0,753 & 24,0 & 11,0 & 9,22 \\
\hline Matayba juglandifolia (Cambess.) Radlk. & 189 & - & 1 & - & 1 & 0,010 & 11,5 & 9,0 & 0,20 \\
\hline SAPOTACEAE & & & & & & & & & \\
\hline $\begin{array}{l}\text { Chrysophyllum marginatum } \\
\text { (Hooker \& Arnot) Radlk. }\end{array}$ & 190 & 19 & 22 & 10 & 18 & 0,341 & 24,1 & 11,0 & 5,38 \\
\hline SIPARUNACEAE & & & & & & & & & \\
\hline Siparuna cujabana (Mart.) A. DC. & 215 & - & + & - & - & - & - & - & - \\
\hline Siparuna guianensis Aublet & 191 & - & 1 & + & 1 & 0,003 & 5,9 & 8,5 & 0,18 \\
\hline SOLANACEAE & & & & & & & & & \\
\hline Cestrum laevigatum Schltdl. & 192 & - & + & - & - & - & - & - & - \\
\hline Solanum lycocarpum A. St.-Hil. & 193 & - & - & + & - & - & - & - & - \\
\hline STYRACACEAE & & & & & & & & & \\
\hline Styrax camporus Pohl & 194 & - & - & + & - & - & - & - & - \\
\hline SYMPLOCACEAE & & & & & & & & & \\
\hline Symplocos pubescens Klotzsch & 195 & 1 & 2 & + & 3 & 0,028 & 14,4 & 9,0 & 0,59 \\
\hline THYMELAEACEAE & & & & & & & & & \\
\hline Daphnopsis brasiliensis Mart. \& Zucc. & 196 & 2 & 1 & - & 3 & 0,023 & 11,5 & 9,5 & 0,58 \\
\hline Daphnopsis fasciculata (Meisner) Nevling & 197 & 1 & 1 & 11 & 10 & 0,117 & 24,2 & 9,5 & 2,17 \\
\hline URTICACEAE & & & & & & & & & \\
\hline Boehmeria caudata Swartz & 198 & 3 & - & - & 1 & 0,011 & 8,8 & 5,0 & 0,28 \\
\hline Urera baccifera (L.) Gaud. & 199 & - & - & + & - & - & - & - & - \\
\hline VERBENACEAE & & & & & & & & & \\
\hline Aegiphila lhotskiana Cham. & 200 & - & - & + & - & - & - & - & - \\
\hline Aegiphila sellowiana Cham. & 201 & - & 1 & 1 & 2 & 0,006 & 7,2 & 7,5 & 0,35 \\
\hline Vitex megapotamica (Sprengel) Moldenke & 202 & 1 & - & - & 1 & 0,004 & 7,2 & 8,5 & 0,18 \\
\hline
\end{tabular}


Tabela 2 (cont.)

\begin{tabular}{|c|c|c|c|c|c|c|c|c|c|}
\hline \multirow{2}{*}{$\begin{array}{l}\text { Famílias } \\
\text { Espécies }\end{array}$} & \multirow[t]{2}{*}{$\mathrm{Rg}$} & \multicolumn{3}{|c|}{ N. ind. } & \multirow[t]{2}{*}{$\mathrm{P}$} & \multirow{2}{*}{$\begin{array}{l}\mathrm{AB} \\
\left(\mathrm{m}^{2}\right)\end{array}$} & \multirow{2}{*}{$\begin{array}{c}\mathrm{d} \\
(\mathrm{cm})\end{array}$} & \multirow{2}{*}{$\begin{array}{l}\mathrm{h} \\
(\mathrm{m})\end{array}$} & \multirow[t]{2}{*}{ VI } \\
\hline & & $\mathrm{Ne}$ & $\mathrm{Ca}$ & $\mathrm{Ar}$ & & & & & \\
\hline \multicolumn{10}{|l|}{ VERBENACEAE } \\
\hline Vitex polygama Cham. & 203 & 1 & 2 & - & 3 & 0,022 & 12,3 & 10,0 & 0,57 \\
\hline \multicolumn{10}{|l|}{ VOCHYSIACEAE } \\
\hline Callisthene major Mart. & 204 & + & - & - & - & - & - & - & - \\
\hline Qualea cordata (Mart.) Sprengel & 205 & - & 2 & - & 2 & 0,017 & 12,7 & 7,5 & 0,39 \\
\hline Vochysia thyrsoidea Pohl & 207 & - & - & 1 & 1 & 0,010 & 11,0 & 5,0 & 0,20 \\
\hline Vochysia tucanorum Mart. & 208 & 1 & 1 & 11 & 9 & 0,128 & 15,9 & 11,0 & 2,08 \\
\hline
\end{tabular}

Tabela 3. Número de espécies (Spp) e de indivíduos (Ind), índice de diversidade de Shannon (H') e equabilidade de Pielou (J') nas 25 parcelas da amostra total e nas 15 parcelas das sub-amostras da comunidade arbórea da Mata da Subestação, Lavras, MG. Letras diferentes indicam diferenças significativas em testes de t para $\mathrm{H}^{\prime}(\mathrm{P}<0,05)$ feitos aos pares entre Neossolo B, Cambissolo e Argissolo.

\begin{tabular}{lrrrcc}
\hline Subgrupos de solos & N & Spp & Ind & $\begin{array}{c}\mathrm{H}^{\prime} \\
\text { (nat.ind }^{-1} \text { ) }\end{array}$ & J' \\
\hline Amostra total & 25 & 140 & 2683 & 3,73 & 0,76 \\
Neossolo B & 5 & 78 & 506 & $3,74 \mathrm{a}$ & 0,86 \\
Cambissolo & 5 & 84 & 496 & $3,57 \mathrm{a}$ & 0,80 \\
Argissolo & 5 & 63 & 596 & $3,10 \mathrm{~b}$ & 0,75 \\
\hline
\end{tabular}

com testes de Kolmogorov-Smirnoff $(\mathrm{P}<0,05)$ comparando as distribuições duas a duas. A densidade de árvores de $>5$ a $10 \mathrm{~m}$ de altura foi maior nos Argissolos que nos Neossolos B e Cambissolos, enquanto que, para a classe de $>10$ a $15 \mathrm{~m}$ de altura, a densidade de árvores foi menor nos Argissolos que nos outros dois solos. No caso dos diâmetros, a diferença mais marcante ocorreu na classe de menor tamanho ( 5 a $10 \mathrm{~cm}$ de DAP), que mostrou uma densidade de árvores crescente dos Neossolos para os Argissolos, que mostraram maior densidade para todas as classes de diâmetro. De uma foram geral, os Argissolos apresentaram uma maior densidade de árvores em geral, principalmente entre as mais finas e mais baixas, enquanto os Cambissolos e Neossolos B mostraram maior densidade de árvores mais altas.

As 11 espécies de maior densidade somaram mais da metade $(55,3 \%)$ dos indivíduos encontrados, indicando forte dominância ecológica na comunidade arbóreo-arbustiva (tabela 2), o que é confirmado pelo valor relativamente baixo de J'. O quadro se repete com a dominância em área basal, pois as nove espécies detentoras dos maiores valores corresponderam a 55,2\% da área basal total (tabela 2).

Distribuição das espécies - Os autovalores da CCA para os dois primeiros eixos de ordenação foram baixos, 0,25 (eixo 1) e 0,07 (eixo 2), indicando a existência de gradientes curtos, ou seja, a maioria das espécies se distribui por todo o gradiente, com algumas delas variando apenas a abundância relativa. Os dois primeiros eixos explicaram apenas $21,3 \%$ (eixo 1) e $6,0 \%$ (eixo 2) da variância global dos dados (total acumulado: 27,2\%), indicando muito 'ruído' ou variância remanescente não explicada. Apesar disso, a significância das relações espécie-ambiente não foi prejudicada, pois a CCA produziu altas correlações espécie-ambiente nos dois primeiros eixos: 0,971 (eixo 1) e 0,871 (eixo 2). Além disso, o teste de permutação de Monte Carlo indicou que as abundâncias das espécies e as variáveis ambientais foram significativamente correlacionadas no primeiro eixo de ordenação $(\mathrm{P}=0,01)$, mas não no segundo eixo $(\mathrm{P}=0,07)$. As variáveis ambientais mais fortemente correlacionadas com o primeiro eixo foram, em ordem decrescente, classe de drenagem, saturação por bases (V), teor de $\mathrm{Al}$ e proporção de areia (tabela 5). Para o segundo eixo, destaca-se a proporção de areia. As correlações ponderadas mostram também inter-relações fortes entre as quatro variáveis, particularmente entre $\mathrm{V}$ e Al e entre drenagem e $\mathrm{V}$, confirmando a tendência de variação catenária para a maioria das propriedades dos solos.

A ordenação das parcelas no primeiro eixo (figura 3A) sugere claramente um gradiente, da esquerda para a direita, que corresponde à catena Argissolos-Cambissolos-Neossolos B. A ordenação separou também, com clareza, os Cambissolos imperfeitamente drenados (D1, E1, G2, H1 e I1) dos moderadamente drenados (A3, B2, C2, F2 e G3) e os Argissolos bem drenados (D2, E2, H2 e H3) dos 
Tabela 4. Densidade e área basal de árvores e arbustos $(\mathrm{DAP} \geq 5 \mathrm{~cm})$ por hectare nas 25 parcelas utilizadas para amostrar a Mata da Ilha, Ingaí, MG. Os valores são médias \pm desvios padrão da amostra total e das $N$ parcelas dos quatro subgrupos de solo. Onde análises de variância indicaram diferenças significativas entre os três solos, (exceto amostra total e Neossolo A), médias seguidas de letras diferentes são significativamente diferentes em testes de Tukey $(\mathrm{p}<0,05)$.

\begin{tabular}{lrcr}
\hline Subgrupos de solos & $N$ & $\begin{array}{c}\text { Densidade } \\
\left(\text { árvores.ha- }{ }^{-1}\right)\end{array}$ & $\begin{array}{c}\text { Área basal } \\
\left(\mathrm{m}^{2} \cdot \mathrm{ha}^{-1}\right)\end{array}$ \\
\hline Amostra total & 25 & $2683 \pm 669$ & $29,31 \pm 8,85$ \\
Neossolo A & 1 & 925 & 19,48 \\
Neossolo B & 5 & $2530 \pm 212 \mathrm{~b}$ & $33,59 \pm 2,42$ a \\
Cambissolo & 10 & $2490 \pm 224 \mathrm{~b}$ & $32,97 \pm 9,17$ ab \\
Argissolo & 9 & $3177 \pm 259 \mathrm{a}$ & $23,95 \pm 8,05 \mathrm{~b}$ \\
ANOVA & & $\mathrm{F}=5,4 ; \mathrm{p}<0,05$ & $\mathrm{~F}=3,9 ; \mathrm{p}<0,05$ \\
\hline
\end{tabular}

acentuadamente drenados (B3, C3, D3, E3 e F3). As correlações com as quatro variáveis ambientais no diagrama são muito claras e o gradiente catenário, da esquerda para a direita, envolve restrição de drenagem, saturação por bases e fração areia crescentes e teor de alumínio decrescente.

A ordenação das espécies pela CCA (figura 3B) sugere que espécies, como Casearia decandra, Vochysia tucanorum, Daphnopsis fasciculata, Campomanesia velutina, Platypodium elegans e Lamanonia ternata, tendem a ser mais abundantes nas áreas com drenagem mais forte, distantes da margem do rio e com predominância de Argissolos. No outro extremo do gradiente, correspondente aos sítios com drenagem mais deficiente, adjacentes ao rio e com predominância dos Neossolos B, concentram-se espécies como Sebastiania commersoniana, S. brasiliensis, Nectandra megapotamica, Luehea divaricata, Gomidesia affinis e Casearia sylvestris. Em condições intermediárias do gradiente, ou indiferentes ao mesmo, relacionam-se espécies como Copaifera langsdorffii, Myrcia multiflora, Macharium villosum, M. hirtum, Tabebuia serratifolia e Tapirira guianensis.

Das 48 espécies analisadas, 24 (49,0\%) apresentaram correlações significativas com as classes de drenagem e $11(22,4 \%)$ com a saturação por bases (V) (tabela 6). Todas as espécies correlacionadas significativamente com $\mathrm{V}$ também o foram com a drenagem. A maioria das espécies que apresentaram correlações significativas também foi ordenada nos extremos do primeiro eixo da CCA. Oito das 12 espécies que aumentaram significativamente sua abundância com o incremento da drenagem dos solos também reduziram significativamente sua abundância com o aumento de V. Apenas quatro espécies aumentaram sua abundância apenas com o incremento da drenagem. Dentre as 12

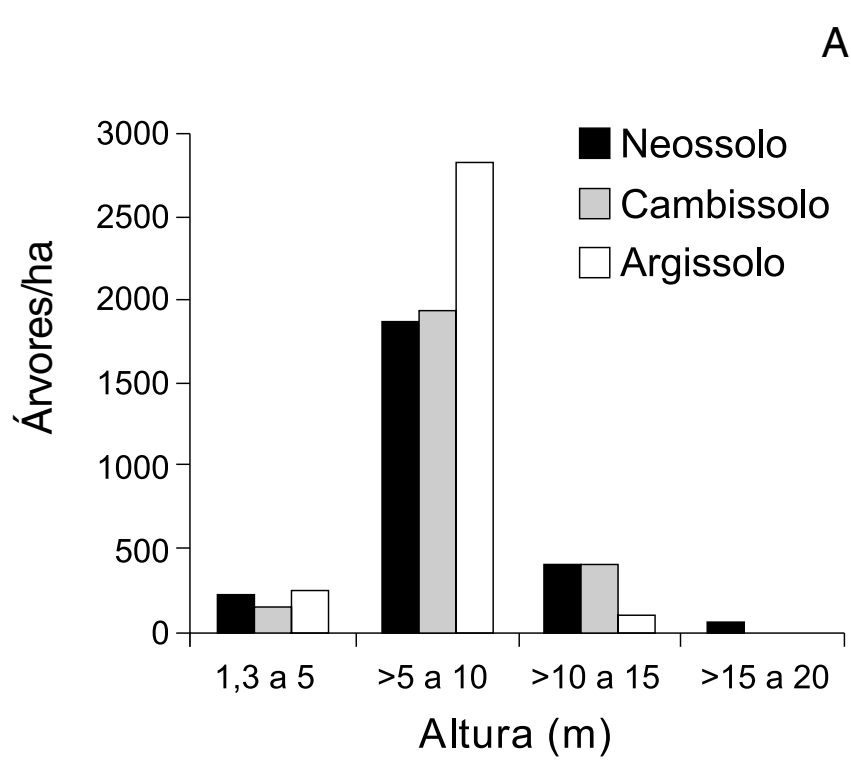

B

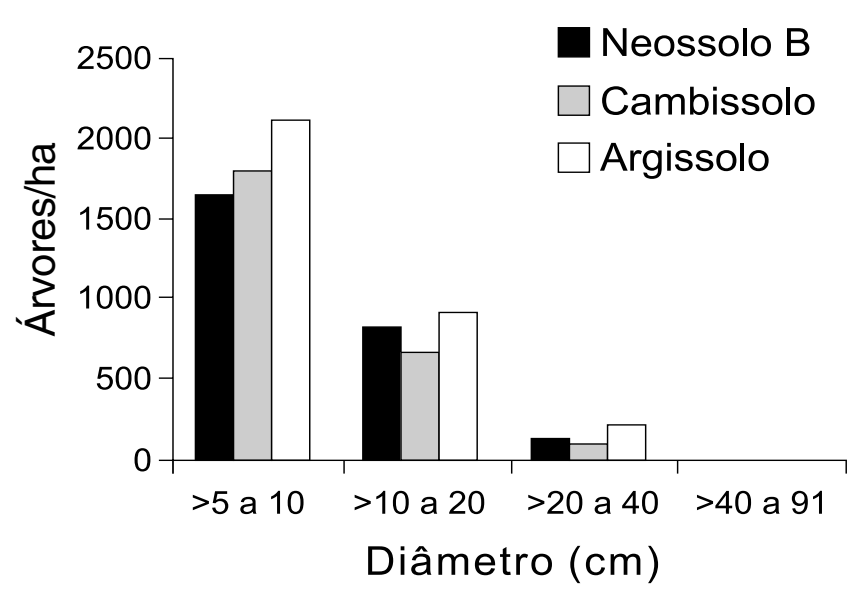

Figura 2. Distribuição da densidade de árvores e arbustos $\geq 5 \mathrm{~cm}$ de DAP em classes de altura (A) e diâmetro (B) nas parcelas utilizadas para amostrar a Mata da Ilha, Ingaí, MG, agrupadas em três subgrupos de solos. 
Tabela 5. Análise de correspondência canônica (CCA): coeficientes canônicos e correlações internas ('intraset') nos dois primeiros eixos de ordenação e matriz de correlações ponderadas para as variáveis ambientais utilizadas na análise. Correlações com valores absolutos $>0,5$ estão indicadas em negrito.

\begin{tabular}{lccccc}
\hline Variáveis ambientais & \multicolumn{2}{c}{ Correlações ponderadas } & Drenagem & V & Al \\
\cline { 2 - 5 } & \multicolumn{2}{c}{ Eixo 1} & Eixo 2 & & \\
\hline Drenagem & $\mathbf{- 0 , 9 9 3}$ & 0,089 & - & - & - \\
V & $\mathbf{0 , 7 5 5}$ & 0,203 & $\mathbf{- 0 , 6 8 2}$ & $-\mathbf{0 , 9 0 7}$ & $-0,496$ \\
Al & $\mathbf{- 0 , 6 5 2}$ & $-0,165$ & $\mathbf{0 , 5 9 2}$ & 0,391 & 0,474 \\
Areia & $\mathbf{0 , 5 1 4}$ & $\mathbf{0 , 7 0 4}$ & & \\
\hline
\end{tabular}

espécies que aumentaram significativamente sua abundância com o aumento da restrição de drenagem, apenas três também aumentaram sua abundância com o aumento de V. As outras nove correlacionaram-se significativamente apenas com o aumento das restrições à drenagem. É importante salientar também que, entre as 25 espécies sem correlações significativas com a drenagem ou V, muitas são bastante abundantes na Mata da Ilha e, portanto, distribuem-se aparentemente de forma indiferente a estas variáveis ambientais. Entre elas estão: Tapirira guianensis, T. obtusa, Protium widgrenii, Eugenia florida, Macherium hirtum, Cupania vernalis e Lithraea molleoides.

\section{Discussão}

Composição florística e diversidade de espécies - O número de espécies registrado para a Mata da Ilha pode ser considerado elevado no contexto regional, como pode ser verificado na comparação com sete levantamentos de fragmentos de florestas estacionais semideciduais, tanto ripárias como de terra firme, realizados com esforço amostral semelhante na região do Alto Rio Grande (Oliveira Filho et al. 1994e, van den Berg \& Oliveira Filho 2000). Dos quatro fragmentos que ultrapassaram as 212 espécies da Mata da Ilha, três estão entre os de maior extensão de toda a região: Tiradentes, com 277 espécies e uma área superior a 1.000 ha, Bom Sucesso, com 241 espécies e área de 84 ha, e Poço Bonito, com 219 espécies e área de 74 ha. A terceira delas, em Itutinga, com 256 espécies, deve sua grande riqueza certamente ao fato de a listagem ser composta da soma de vários pequenos fragmentos existentes na margem do Reservatório Hidrelétrico de Camargos e cuja área total não foi computada pelos autores. Os três fragmentos com número de espécies inferior ao da Mata da Ilha foram os de Camargos (162 espécies e 7,5 ha), Madre de Deus de Minas (192 espécies e 20 ha) e Lavras/UFLA (184 espécies e 6 ha).

Uma riqueza de espécies relativamente elevada é característica comum em florestas ciliares devido a uma heterogeneidade ambiental comumente superior à de florestas de terra firme próximas (Oliveira Filho et al. 1990). Segundo Rodrigues \& Nave (2000), este fato é condicionado pela natureza ecotonal da faixa ciliar, que é ocupada por mais de um tipo vegetacional ou mesmo por formações fitofisionômicas distintas, que diferem fortemente entre si em termos de composição florística. Sendo assim, no caso da Mata da Ilha, o número de espécies relativamente alto recebe, certamente, uma forte contribuição da heterogeneidade ambiental causada pelo ecótono mata ciliar-mata de terra firme (as formas aluvial e montana da floresta semidecidual) e pelo contato destas com as formações de cerrado que predominavam nas adjacências da floresta (hoje bastante degradados) e que ainda ocorrem na mancha de cerradão do interior do fragmento. Este fato, provavelmente, explica a ocorrência de espécies típicas de matas ciliares juntamente com espécies típicas do cerrado, tais como Tabebuia ochracea, Bowdichia virgilioides, Caryocar brasiliense, Schefflera macrocarpa, Brosimum gaudichaudii, Myrsine guianensis, Dalbergia miscolobium, Rudgea viburnoides e Austroplenkia populnea. Além disso, seis entre as dez espécies de maior densidade na amostragem, Copaifera langsdorffii, Myrsine umbellata, Tapirira guianensis, T. obtusa, Casearia sylvestris e Platypodium elegans, também são espécies integrantes da flora do cerrado sensu lato e reconhecidas como generalistas de ampla distribuição (Ratter et al. 1996). É bem possível que a Mata da Ilha represente um sítio de expansão sucessional de mata ciliar sobre cerrado em áreas protegidas contra o fogo, conforme detectado em outras partes do Brasil Central (Oliveira-Filho \& Ratter 1995). Sua situação, alojada no interior de um meandro fechado do rio Ingaí, poderia 
Tabela 6. Coeficientes de correlação de Spearman e sua significância (p) entre a abundância de 48 espécies arbóreas e as classes de drenagem e saturação por bases dos solos. $N=24$ parcelas de $20 \times 20 \mathrm{~m}$ de floresta semidecídua na Mata da Ilha, Ingaí, MG. Espécies ordenadas por correlações decrescentes com as classes de drenagem. Os nomes abreviados identificam as espécies na figura $3 \mathrm{~B}$.

\begin{tabular}{|c|c|c|c|c|c|}
\hline Espécie & Nomes Abreviados & Classes de drenagem & $\mathrm{P}$ & V (saturaçãopor bases) & $\mathrm{P}$ \\
\hline Myrsine umbellata & Myrs umb & 0,884 & $* * *$ & $-0,548$ & $* * *$ \\
\hline Copaifera langsdorffii & Copa lan & 0,786 & $* * *$ & $-0,600$ & $* * *$ \\
\hline Platypodium elegans & Plat ele & 0,741 & $* * *$ & $-0,609$ & $* * *$ \\
\hline Myrcia tomentosa & Myrc tom & 0,621 & $* * *$ & $-0,349$ & $\mathrm{~ns}$ \\
\hline Daphnopsis fasciculata & Daph faz & 0,586 & $* * *$ & $-0,187$ & $\mathrm{~ns}$ \\
\hline Lamanonia ternata & Lama ter & 0,571 & $* * *$ & $-0,413$ & $*$ \\
\hline Simira sampaioana & Simi sam & 0,565 & $* * *$ & $-0,756$ & $* * *$ \\
\hline Vochysia tucanorum & Voch tuc & 0,556 & $* * *$ & $-0,321$ & $\mathrm{~ns}$ \\
\hline Casearia decandra & Case dec & 0,530 & $* *$ & $-0,508$ & ** \\
\hline Myrcia rostrata & Myrc ros & 0,417 & $*$ & $-0,407$ & $*$ \\
\hline Matayba elaeagnoides & Mata ela & 0,384 & $*$ & $-0,291$ & $\mathrm{~ns}$ \\
\hline Myrcia venulosa & Myrc ven & 0,383 & $*$ & $-0,622$ & $* * *$ \\
\hline Luehea grandiflora & Lueh grã & 0,336 & $\mathrm{~ns}$ & $-0,272$ & $\mathrm{~ns}$ \\
\hline Campomanesia velutina & Camp vel & 0,324 & $\mathrm{~ns}$ & $-0,163$ & $\mathrm{~ns}$ \\
\hline Protium widgrenii & Prot wid & 0,307 & $\mathrm{~ns}$ & $-0,379$ & $\mathrm{~ns}$ \\
\hline Myrcia multiflora & Myrc mul & 0,228 & $\mathrm{~ns}$ & $-0,133$ & $\mathrm{~ns}$ \\
\hline Machaerium villosum & Mach vil & 0,222 & $\mathrm{~ns}$ & $-0,132$ & $\mathrm{~ns}$ \\
\hline Guettarda viburnoides & Guet vib & 0,198 & $\mathrm{~ns}$ & 0,034 & $\mathrm{~ns}$ \\
\hline Ocotea pulchella & Ocot pul & 0,182 & $\mathrm{~ns}$ & $-0,187$ & $\mathrm{~ns}$ \\
\hline Lafoensia pacari & Lafo pac & 0,159 & $\mathrm{~ns}$ & 0,033 & $\mathrm{~ns}$ \\
\hline Siphoneugena densiflora & Siph den & 0,107 & $\mathrm{~ns}$ & $-0,052$ & $\mathrm{~ns}$ \\
\hline Tapirira obtusa & Tapi obt & 0,084 & $\mathrm{~ns}$ & $-0,234$ & $\mathrm{~ns}$ \\
\hline Tabebuia serratifolia & Tabe ser & 0,065 & $\mathrm{~ns}$ & $-0,190$ & $\mathrm{~ns}$ \\
\hline Andira fraxinifolia & Andi fra & $-0,051$ & $\mathrm{~ns}$ & $-0,030$ & $\mathrm{~ns}$ \\
\hline Bauhinia longifólia & Bauh lon & $-0,054$ & $\mathrm{~ns}$ & 0,118 & $\mathrm{~ns}$ \\
\hline Tapirira guianensis & Tapi gui & $-0,072$ & $\mathrm{~ns}$ & $-0,169$ & $\mathrm{~ns}$ \\
\hline Xylosma ciliatifolium & Xylo cil & $-0,073$ & $\mathrm{~ns}$ & 0,248 & $\mathrm{~ns}$ \\
\hline Nectandra nitidula & Nect nit & $-0,126$ & $\mathrm{~ns}$ & 0,268 & $\mathrm{~ns}$ \\
\hline Cordia trichotoma & Cord tri & $-0,168$ & $\mathrm{~ns}$ & 0,111 & $\mathrm{~ns}$ \\
\hline Lithraea molleoides & Lith mol & $-0,192$ & $\mathrm{~ns}$ & 0,145 & $\mathrm{~ns}$ \\
\hline Eugenia florida & Euge flo & $-0,200$ & $\mathrm{~ns}$ & 0,152 & $\mathrm{~ns}$ \\
\hline Cupania vernalis & Cupa ver & $-0,249$ & $\mathrm{~ns}$ & 0,162 & $\mathrm{~ns}$ \\
\hline Machaerium hirtum & Mach hir & $-0,284$ & $\mathrm{~ns}$ & 0,373 & $\mathrm{~ns}$ \\
\hline Sebastiania brasiliensis & Seba bra & $-0,321$ & $\mathrm{~ns}$ & 0,326 & $\mathrm{~ns}$ \\
\hline Chrysophyllum marginatum & Chry mar & $-0,337$ & $\mathrm{~ns}$ & 0,298 & $\mathrm{~ns}$ \\
\hline Rollinia emarginata & Roll ema & $-0,347$ & $\mathrm{~ns}$ & 0,122 & $\mathrm{~ns}$ \\
\hline Prunus brasiliensis & Prun bra & $-0,366$ & $\mathrm{~ns}$ & 0,294 & $\mathrm{~ns}$ \\
\hline Sebastiania commersoniana & Seba com & $-0,374$ & $*$ & 0,327 & $\mathrm{~ns}$ \\
\hline Croton urucurana & Crot uru & $-0,383$ & * & 0,340 & $\mathrm{~ns}$ \\
\hline Campomanesia guazumifolia & Camp gua & $-0,393$ & $*$ & 0,145 & $\mathrm{~ns}$ \\
\hline Gomidesia affinis & Gomi aff & $-0,410$ & $*$ & 0,279 & $\mathrm{~ns}$ \\
\hline Machaerium nictitans & Mach nic & $-0,444$ & $*$ & 0,192 & $\mathrm{~ns}$ \\
\hline Actinostemon concolor & Acti con & $-0,445$ & * & 0,367 & $\mathrm{~ns}$ \\
\hline Chomelia sericea & Chom ser & $-0,505$ & $*$ & 0,214 & $\mathrm{~ns}$ \\
\hline Dendropanax cuneatus & Dend cun & $-0,522$ & $* *$ & 0,344 & $\mathrm{~ns}$ \\
\hline Machaerium stipitatum & Mach sti & $-0,535$ & $* *$ & 0,468 & $*$ \\
\hline Nectandra megapotamica & Nect meg & $-0,640$ & $* * *$ & 0,255 & $\mathrm{~ns}$ \\
\hline Luehea divaricata & Lueh div & $-0,722$ & $* * *$ & 0,405 & $*$ \\
\hline Casearia sylvestris & Case syl & $-0,902$ & $* * *$ & 0,559 & $* * *$ \\
\hline
\end{tabular}

$* \mathrm{p}<0,05, * * \mathrm{p}<0,01 ; * * * \mathrm{p}<0,001, \mathrm{~ns}=$ não significativo. 
ter conferido maior proteção contra a expansão dos incêndios e a mancha de cerradão no interior do fragmento poderia ser um remanescente do cerrado original. Por outro lado, também não se pode descartar

A
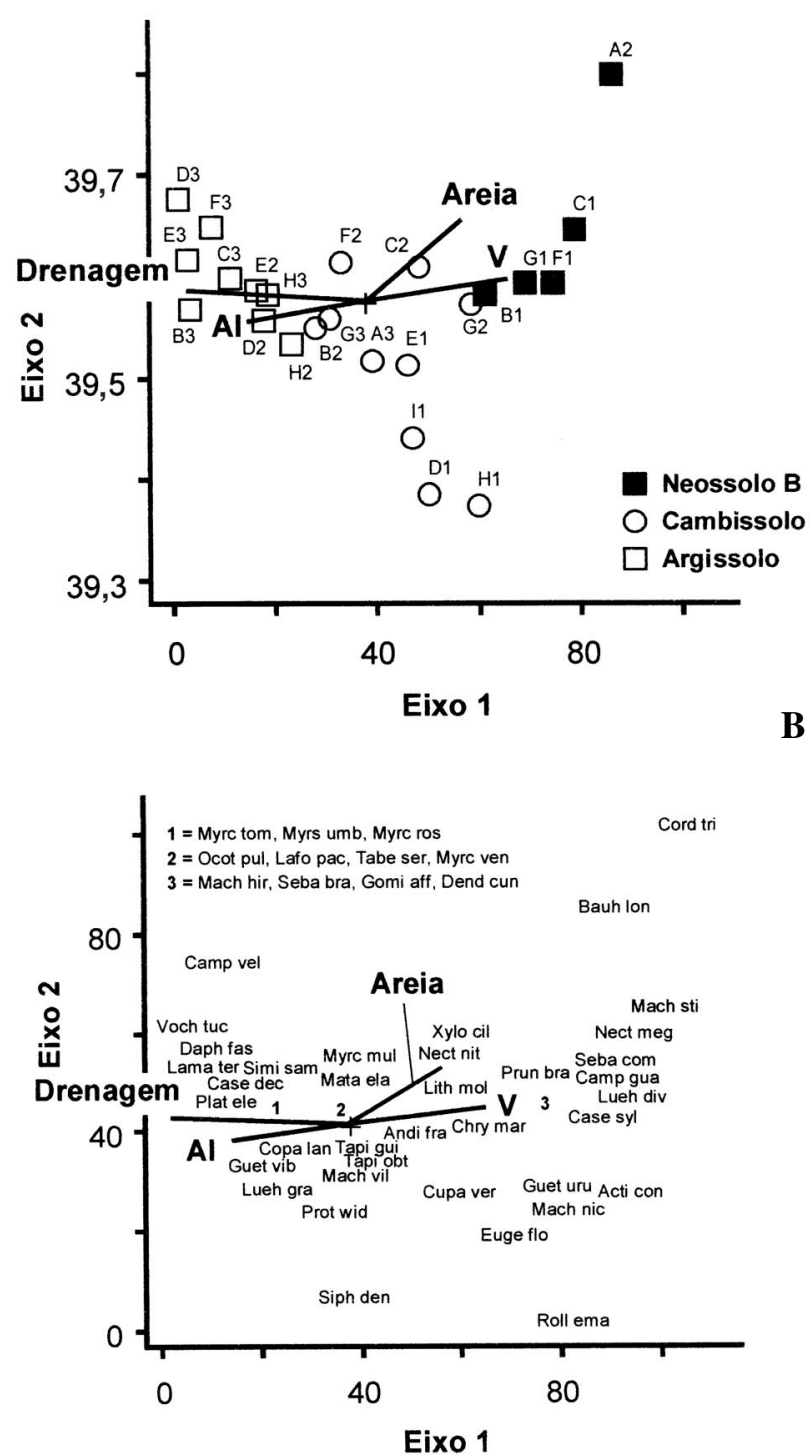

Figura 3. Análise de correspondência canônica: diagrama de ordenação das parcelas (A) e espécies (B) baseada na distribuição do número de indivíduos de 48 espécies em 24 parcelas de floresta semidecídua, Mata da Ilha, Ingaí, MG, e sua correlação com as quatro variáveis ambientais utilizadas (setas). As parcelas são identificadas pelo seu nome (vide figura 1) e classificadas nos três subgrupos de solo. As espécies são indicadas pelo seu nome abreviado (correspondência com nomes completos na Tabela 6); a coordenada de ordenação está na primeira inicial do nome. Drenagem = classes de drenagem; $\mathrm{V}=$ saturação por bases; $\mathrm{Al}=$ teor de alumínio; Areia = proporção de areia. a possibilidade de que a floresta esteja ainda se recuperando de um distúrbio mais antigo que o alcance da memória dos habitantes locais. Somente estudos futuros de dinâmica poderão esclarecer mais esta questão.

O perfil florístico do fragmento confirma a observação de Leitão Filho (1987) de que as famílias de maior riqueza nas matas ciliares do Centro-Sul do Brasil são Myrtaceae, Lauraceae, Fabaceae, Euphorbiaceae e Rubiaceae. A listagem florística apresentou, ainda, muitas espécies já reconhecidas como de ocorrência comum em matas ciliares, como Tapirira guianensis, Hymenaea courbaril, Copaifera langsdorffii, Protium heptaphyllum e Casearia sylvestris, todas consideradas, de uma maneira geral, como generalistas por habitat (Oliveira Filho \& Ratter 1995, 2000). Segundo Durigan et al. (2000), as matas ciliares apresentam uma combinação de espécies arbóreas de distribuição ampla e restrita, conforme ocorram em várias ou poucas unidades fitogeográficas, respectivamente. Das espécies aqui relacionadas, $22,2 \%$ constam na lista das espécies encontradas em mais de $24 \%$ dos 43 levantamentos realizados em Minas Gerais, São Paulo e Mato Grosso e relacionados por Rodrigues \& Nave (2000), podendo ser vistas como de ampla distribuição. Desta forma, o expressivo número de espécies registrado na Mata da Ilha pode ser creditado principalmente a uma soma de espécies de florestas da região e espécies comuns de matas ciliares em geral.

Mesmo com um número de espécies relativamente alto, o índice de diversidade de Shannon encontrado para a Mata da Ilha $\left(\mathrm{H}^{\prime}=3,734\right)$ está entre os valores mais baixos encontrados em levantamentos de florestas semidecíduas da região. Das seis florestas relacionadas por Oliveira Filho et al. (1994e) e van den Berg \& Oliveira Filho (2000), cinco apresentaram valores de H' superiores ao da Mata da Ilha. Como as amostragens apresentaram valores de riqueza parecidos, entre $118 \mathrm{e}$ 141 espécies, as diferenças de H' devem ser creditadas principalmente às variações da equabilidade de Pielou (J') entre as áreas. De fato, a Mata da Ilha apresentou um valor de J' $(0,756)$ entre os mais baixos dos levantamentos comparados, com apenas uma área abaixo, a Reserva da UFLA, com J' =0,73. Esse baixo valor indica uma alta concentração de abundâncias por parte de algumas espécies. O predomínio em número ou massa de poucas espécies em uma comunidade, também conhecido como dominância ecológica, não é incomum em florestas tropicais (Richards 1952), particularmente entre as florestas estacionais do Brasil Central (Oliveira Filho \& Ratter 2000). 
A forte dominância ecológica encontrada na Mata da Ilha foi marcante principalmente na área nuclear melhor drenada, ou seja, nos Argissolos. Daí, pode-se inferir que, nos solos com menor disponibilidade de água e de fertilidade química mais baixa, houve dominância ecológica mais forte. É comum em florestas tropicais que a dominância ecológica seja mais pronunciada nos extremos de alta e baixa disponibilidade de recursos do solo, resultando em diversidade de espécies mais elevada em condições intermediárias (Ashton 1990). Uma outra característica importante do fragmento estudado foi a presença de um grande número de espécies raras, o que é, na verdade, outro aspecto da forte dominância ecológica. Contudo, uma alta riqueza de espécies com baixa densidade é também uma característica comum em florestas tropicais em geral (Whitmore 1990). Comparando a percentagem de espécies raras calculada para a área de estudo $(28,57 \%$ dos indivíduos) com a amplitude encontrada na floresta Amazônica $(25,14 \%$ a 56,02\%) e na mata Atlântica $(9,23 \%$ a 39,52\%), ambas citadas por Martins (1991), pode-se dizer que a Mata da Ilha apresenta valores intermediários.

Estrutura da comunidade arbóreo-arbustiva Comparando-se com levantamentos feitos na região empregando o mesmo critério de inclusão (DAP $\geq 5 \mathrm{~cm}$ ), a área basal por hectare da Mata da Ilha, de $29,31 \mathrm{~m}^{2} \cdot \mathrm{ha}^{-1}$, foi semelhante às dos fragmentos da Mata do Capivari, em Lavras (Souza 2001), de 27,70 $\mathrm{m}^{2} \cdot \mathrm{ha}^{-1}$, Mata do Galego, em Luminárias (Rodrigues 2001), de $28,33 \mathrm{~m}^{2}$.ha-1, e Mata da Subestação, em Lavras (Espírito-Santo 2000), de 27,24 $\mathrm{m}^{2}$.ha ${ }^{-1}$, todos eles bem superiores à área basal de 19,77 $\mathrm{m}^{2}$.ha-1 da Reserva Florestal da UFLA (Oliveira Filho et al. 1994b). Por outro lado, a densidade da Mata da Ilha, de 2.683 árvores.ha ${ }^{-1}$ é a maior entre as cinco florestas, sendo seguida pela Mata do Galego, com 1.830 árvores.ha $^{-1}$; pela Mata da Subestação, com 1.500 árvores.ha $^{-1}$; Mata do Capivari, com 1.488 árvores.ha $^{-1}$ e Reserva da UFLA, com 1.295 árvores.ha ${ }^{-1}$. A densidade excepcionalmente alta na Mata da Ilha, a despeito de uma área basal semelhante, indica uma densidade de árvores finas mais elevada, característica esta particularmente marcante nos Argissolos. Quase dois terços dos indivíduos amostrados tinham DAP entre 5 e $10 \mathrm{~cm}$.

É bem conhecido que a densidade e a área basal das florestas tropicais variam muito com as condições de solo, água e luz, bem como entre estádios de regeneração. Geralmente, florestas em estádios iniciais de regeneração formam grandes adensamentos de árvores finas (Uhl \& Murphy 1981, Parthasarathy 1991). Contudo, no presente caso, a floresta tem apenas um histórico de leves perturbações pelo homem, pelo menos nos últimos 80 anos (idade do informante mais velho). Desta forma, se a alta densidade de árvores finas realmente reflete um estádio inicial de sucessão, esta poderia resultar da lenta evolução de cerrado para floresta, condicionada por uma maior proteção contra o fogo, conforme sugerido anteriormente. Entretanto, a baixa disponibilidade de recursos do solo (água e nutrientes) nos Argissolos, onde se concentra a alta densidade de árvores finas, pode também resultar em baixa produtividade líquida e, conseqüentemente, maior restrição ao desenvolvimento das árvores. Somente estudos futuros de dinâmica poderão esclarecer se estão havendo mudanças direcionais ou então a manutenção de características que são peculiares a esta comunidade.

A espécie com maior densidade na amostra da Mata da Ilha, Copaifera langsdorffii, também superou as outras espécies em dominância e em frequiência, não ocorrendo em apenas duas delas. Além disso, C. langsdorffii destaca-se ainda pelo grande porte alcançado por suas árvores na Mata da Ilha. Esta espécie tem sido apontada como uma das mais abundantes nas florestas semidecíduas da região, tanto nas ripárias como nas de terra firme, e como bastante generalista quanto ao habitat (Oliveira Filho et al. 1994b, 1995, van den Berg \& Oliveira Filho 1999).

Apenas um grupo restrito de espécies ocorreu com freqüência elevada nas 25 parcelas, indicando que uma distribuição ampla não foi uma característica da maioria das populações. Isto poderia estar refletindo uma distribuição preferencial das espécies em relação aos diferentes habitats amostrados pelas parcelas dentro do fragmento. Como exemplo, podemos citar os extremos das espécies Croton urucurana e Tapirira guianensis. A primeira foi representada por 16 indivíduos em uma única parcela e a segunda por 171 indivíduos em 23 parcelas. Ambas se enquadram, segundo Durigan et al. (2000), no padrão das espécies cuja densidade varia localmente dependendo da extensão de seus habitats preferenciais. Desta forma, Tapirira guianensis ocorre com alta densidade e ampla distribuição provavelmente devido a seu caráter generalista por habitats. Isto já não acontece com Croton urucurana, espécie característica de solos sujeitos a inundações periódicas (Lorenzi 1992), habitat que ocorreu apenas na única parcela de Argissolo A.

Distribuição das espécies - Os solos de matas ciliares apresentam comumente uma alta heterogeneidade 
espacial em suas características (Jacomine 2000). Os solos com textura mais arenosa foram os Neossolos Flúvicos Psamíticos típicos (Neossolos B) situados mais próximos à margem do rio. Estas áreas são ocasionalmente inundadas e a textura mais grossa dos solos provavelmente tem origem na deposição periódica de sedimentos trazidos pelo rio. Já os Neossolos Flúvicos Tb Eutróficos gleicos (Neossolos A), situados em cotas mais baixas sofrem prolongadas inundações e apresentaram níveis mais elevados de bases trocáveis e percentagens menores de areia em sua textura. Neossolos Flúvicos freqüentemente apresentam uma grande heterogeneidade nas propriedades químicas e texturais, normalmente ocasionada por diferenças no tempo de residência da água das inundações e na direção e velocidade da vazão (Oliveira Filho et al. 1994d, Jacomine 2000).

É comum que a fertilidade química dos solos de uma catena cresça do topo para a base da encosta, o que também coincide com um aumento do conteúdo de água (Resende et al. 1988). Esta tendência se repetiu no presente caso, pois os Neossolos Flúvicos apresentaram fertilidade química mais elevada e drenagem mais restrita enquanto os Argissolos Vermelhos foram os mais pobres em nutrientes e os melhor drenados, ficando os Cambissolos Háplicos da meia encosta com características intermediárias. Em geral, tais diferenças devem-se à exportação de material das partes mais altas para as mais baixas, podendo ainda ser incrementado, como no presente caso, pela sedimentação nos leitos aluviais (Resende et al. 1995). Desta maneira, o gradiente Neossolo-Cambissolo-Argissolo corresponde a um declínio na disponibilidade tanto de água como de nutrientes minerais.

O gradiente catenário identificado na Mata da Ilha foi claramente correspondido pela distribuição das espécies da comunidade arbóreo-arbustiva. Apesar das variações significativas na fertilidade química dos solos com o relevo, é bem possível que seja o regime de água o principal fator ambiental associado à distribuição das espécies arbóreo-arbustivas na área, conforme já detectado em outras matas ciliares (van den Berg \& Oliveira Filho 1999, Oliveira Filho et al. 1994c, 1994d, 1997, Schiavini 1997, Silva Junior et al. 1996, Silva Junior 1997). Também não se pode descartar a influência da variação das condições de luz ocasionada pelo espaço do rio e pela estrutura da vegetação.

Algumas espécies correlacionadas com o extremo de menor disponibilidade de água e nutrientes, tais como Vochysia tucanorum, Myrcia tomentosa, M. rostrata, Daphnopsis fasciculata, Platypodium elegans,
Lamanonia ternata e Guettarda viburnoides, já foram caracterizadas desta forma por outros autores (Lorenzi 1992, 1998, Oliveira Filho et al. 1995, Rodrigues \& Nave 2000). O outro extremo do gradiente, representado por solos mais ricos e sob influência direta do curso d'água, foi caracterizado por espécies comumente associadas ao ambiente ripário, como Croton urucurana, Sebastiania commersoniana, S. brasiliensis, Nectandra megapotamica e Luehea divaricata (Lorenzi 1992, 1998; Oliveira Filho et al. 1995).

É preciso ter cautela na interpretação de certas correlações entre a distribuição de espécies e variáveis do ambiente físico. Muitas vezes espécies encontradas em condições preferencialmente ripárias podem estar distribuídas nas margens dos rios condicionadas principalmente pela maior luminosidade propiciada pela abertura do rio (Oliveira Filho et al. 1994d). Este pode ser o caso de Casearia sylvestris, significativamente mais abundante nas margens do rio Ingaí, na Mata da Ilha, mas também comum na região em áreas mais secas porém bem iluminadas, como bordas de fragmentos florestais e o próprio cerrado. Fato semelhante acontece com Machaerium stipitatum e Actinostemon concolor, que também podem ocorrer com abundância na região em áreas mais secas e de menor fertilidade (Oliveira-Filho et al. 1994c). O fato contrário também pode ocorrer. Myrsine umbellata, que foi significativamente mais abundante nos solos mais secos e de fertilidade mais baixa na Mata da Ilha, é abundante em muitas florestas ripárias da região, incluindo as paludosas.

Muitas espécies abundantes na Mata da Ilha são consideradas como amplos generalistas por habitat de solo, como Tapirira obtusa, T. guianensis, Tabebuia serratifolia e Myrsine umbellata, ou generalistas com certa preferência, como Copaifera langsdorffii e Protium widgrenii, mais comuns em solos bem drenados e de fertilidade química mais baixa, e Cupania vernalis, Machaerium nictitans, M. villosum e Lithraea molleoides, mais comuns em solos bem drenados e de fertilidade química intermediária a mais alta (Oliveira-Filho et al. 1995). Estas espécies realmente distribuíram-se de maneira ampla na Mata da Ilha, embora algumas delas tenham se concentrado em um dos extremos do gradiente catenário.

$\mathrm{Na}$ interpretação da distribuição de espécies em consonância com as variáveis ambientais é sempre preciso cautela, pois variáveis fundamentais, como as condições de luz e água e os fatores de dispersão das espécies, nem sempre são facilmente perceptíveis ou mensuráveis. Além disso, as espécies são sensíveis às 
variáveis ambientais de uma forma interativa e não isoladamente, além de responder a elas num ambiente de competição entre espécies. Desta maneira, conclusões sobre a distribuição de espécies face a variáveis ambientais só devem se aproximar de uma generalização após muitas repetições do mesmo padrão em diversas áreas.

\section{Referências bibliográficas}

APG (ANGIOSPEM PHYLOGENY GROUP). 1998. An ordinal classification for the families of flowering plants. Annals of the Missouri Botanical Garden 85:531-553.

ASHTON, P.S. 1990. Species richness in tropical forests. In Tropical forests - botanical dynamics, speciation and diversity (L.B. Holm-Nielsen, I.C. Nielsen \& H. Balslev, eds.). Academic Press, London, p.239-251.

BARRELLA, W., PETRERE JÚNIOR, M., SMITH, W.S. \& MONTAG, L.F.A. 2000. As relações entre as matas ciliares, os rios e os peixes. In Matas Ciliares: conservação e recuperação (R.R. Rodrigues \& H.F. Leitão Filho, eds.). EDUSP, São Paulo, p.187-207.

BROWER, J.E. \& ZAR, J.H. 1984. Field and laboratory methods for general ecology. W.M.C. Brow, Dubuque.

DURIGAN, G., RODRIGUES, R.R. \& SCHIAVINI, I. 2000. A heterogeneidade ambiental definindo a metodologia de amostragem da floresta ciliar. In Matas ciliares: conservação e recuperação (R.R. Rodrigues \& H.F. Leitão Filho, eds.). EDUSP, São Paulo, p.159-167.

EIDT, R.C. 1968. The climatology of South America. In Biogeography and ecology in South America (E.J. Fittkau, J. Illies, H. Klinge, G.H. Schwabe \& H. Sioli, eds.). W. Junk Publishing, The Hague, v.1, p.54-81.

EMBRAPA. 1997. Manual de métodos de análises de solo. $2^{a}$ ed. Empresa Brasileira de Pesquisa Agropecuária, Centro Nacional de Pesquisa de Solos. Rio de Janeiro.

EMBRAPA. 1999. Sistema brasileiro de classificação de solos. Empresa Brasileira de Pesquisa Agropecuária, Centro Nacional de Pesquisa de Solos. Rio de Janeiro.

ESPIRITO-SANTO, F.D.B. 2000. Estudo do efeito da fragmentação florestal em um fragmento de floresta semidecidual montana, no campus da UFLA. Monografia de graduação, Universidade Federal de Lavras, Lavras.

JACOMINE, P.K.T. 2000. Solos sob matas ciliares. In Matas ciliares: conservação e recuperação (R.R. Rodrigues \& H.F. Leitão Filho, eds.). EDUSP, São Paulo, p.27-31.

KAGEYAMA, P. \& GANDARA, F.B. 1993. Dinâmica de populações de espécies arbóreas implicações para o manejo e a conservação. In Simpósio de Ecossistemas da Costa Brasileira, Universidade de São Paulo, São Paulo, v.3, p.1-12.

LEITÃO FILHO, H.F. 1987. Considerações sobre a florística de florestas tropicais e sub-tropicais do Brasil. Revista do IPEF 35:41-46.
LIMA, W.P. \& ZAKIA, M.J.B. 2000. Hidrologia de matas ciliares. In Matas Ciliares: conservação e recuperação (R.R. Rodrigues \& H.F. Leitão Filho, eds.). EDUSP, São Paulo, p.33-44.

LORENZI, H. 1992. Árvores brasileiras: manual de identificação e cultivo de plantas arbóreas nativas do Brasil. Plantarum, Nova Odessa, v.1.

LORENZI, H. 1998. Árvores brasileiras: manual de identificação e cultivo de plantas arbóreas nativas do Brasil. Plantarum, Nova Odessa, v.2.

MARINHO-FILHO, J. \& GASTAL, M.L. 2000. Mamíferos das matas ciliares dos cerrados do Brasil Central. In Matas Ciliares: conservação e recuperação (R.R. Rodrigues \& H.F. Leitão Filho, eds.). EDUSP, São Paulo, p.209-221.

MARTINS, F.R. 1991. Estrutura de uma floresta mesófila. Editora da UNICAMP, Campinas.

McCUNE, B. \& MEFFORD, M.J. 1999. PC-ORD version 4.0, multivariate analysis of ecological data, Users guide. MjM Software Design, Glaneden Beach.

MUELER-DOMBOIS, D. \& ELLENBERG, H. 1974. Aims and methods of vegetation ecology. John Wiley \& Sons, New York.

OLIVEIRA FILHO, A.T. \& RATTER, J.A. 1995. A study of the origin of central Brazilian forests by the analysis of plant species distribution patterns. Edinburgh Journal of Botany 52:141-194.

OLIVEIRA FILHO, A.T. \& RATTER, J.A. 2000. Padrões florísticos das matas ciliares da região dos cerrados e a evolução das paisagens do Brasil Central durante o Quaternário tardio. In Matas ciliares: conservação e recuperação (R.R. Rodrigues \& H.F. Leitão Filho, eds.). EDUSP, São Paulo, p.73-89.

OLIVEIRA FILHO, A.T., RATTER, J.A. \& SHEPHERD, G.J. 1990. Floristic composition and community structure of a central Brazilian gallery forest. Flora 184:103-117.

OLIVEIRA FILHO, A.T., ALMEIDA, R.J., MELLO, J.M. \& GAVILANES, M.L. 1994a. Estrutura fitossociológica e variáveis ambientais em um trecho da mata ciliar do córrego dos Vilas Boas, Reserva Biológica do Poço Bonito, Lavras (MG). Revista Brasileira de Botânica 17:67-85.

OLIVEIRA FILHO, A.T., SCOLFORO, J.R. \& MELLO, J.M. 1994b. Composição florística e estrutura comunitária de um remanescente de floresta semidecídua montana em Lavras (MG). Revista Brasileira de Botânica 17:159-174.

OLIVEIRA FILHO, A.T., VILELA, E.A., CARVALHO, D.A. \& GAVILANES, M.L. 1994c. Effects of soils and topography on the distribution of tree species in a tropical riverine forest in south-eastern Brazil. Journal of Tropical Ecology 10:483-508. 
OLIVEIRA FILHO, A.T., VILELA, E.A., GAVILANES, M.L. \& CARVALHO, D.A. 1994d. Comparison of the woody flora and soils of six areas of montane semideciduous forest in southern Minas Gerais, Brazil. Edinburgh Journal of Botany 51:355-389.

OLIVEIRA FILHO, A.T., VILELA, E.A., GAVILANES, M.L. \& CARVALHO, D.A. 1994e. Effect of flooding regime and understorey bamboos on the physiognomy and tree species composition of a tropical semideciduous forest in Southeastern Brazil. Vegetatio 113:99-124.

OLIVEIRA FILHO, A.T., VILELA, E.A., CARVALHO, D.A. \& GAVILANES, M.L. 1995. Estudos florísticos e fitossociológicos em remanescentes de matas ciliares do Alto e Médio Rio Grande. Boletim técnico 11.106MA/PA-013. Companhia Energética de Minas Gerais, Belo Horizonte.

OLIVEIRA FILHO, A.T., CURI, N., VILELA, E.A. \& CARVALHO, D.A. 1997. Tree species distribution along soil catenas in a riverside semideciduous forest in Southeastern Brazil. Flora 192:47-64.

OLIVEIRA FILHO, A.T., CURI, N., VILELA, E.A. \& CARVALHO, D.A. 2001. Variation in tree community composition and structure with changes in soil properties within a fragment of semideciduous forest in southeastern Brazil. Edinburgh Journal of Botany 58:139-158

PARTHASARATHY, N. 1991. Tree diversity and distribution in undisturbed and human-impacted sites of tropical wet evergreen Forest in southern Western Ghats, India. Biodiversity and Conservation 8:1365-1381.

QUEIROZ, R., SOUZA, A.G., SANTANA, P., ANTUNES, F.Z. \& FONTES, M. 1980. Zoneamento Agroclimático do Estado de Minas Gerais. Secretaria da Agricultura, Belo Horizonte.

RATTER, J.A., BRIDGEWATER, S., ATKINSON, R. \& RIBEIRO, J.F. 1996. Analysis of the floristic composition of the Brazilian cerrado vegetation II: Comparision of the woody vegetation of 98 areas. Edinburgh Journal of Botany 53:153-180.

RESENDE, M., CURI, N. \& SANTANA, D.P. 1988. Pedologia e fertilidade do solo: interações e interpretações. Ministério da Agricultura, Brasília, e Universidade Federal de Lavras, Lavras.

RESENDE, M., CURI, N., REZENDE, S.B. \& CORRÊA, G.F. 1995. Pedologia: Bases para distinção de ambiente. Núcleo de Estudo de Planejamento e Uso do Terra, Viçosa.

RICHARDS, P.W. 1952. The tropical rain forest. Cambridge University Press, Cambridge.

RODRIGUES, L.A. 2001. Estudo florístico e estrutural da comunidade arbustiva e arbórea de uma floresta em Luminárias, MG, e informações etnobotânicas da população local. Dissertação de mestrado, Universidade Federal de Lavras, Lavras.

RODRIGUES, R.R. \& NAVE, A.G. 2000. Heterogeneidade florística das matas ciliares. In Matas Ciliares: conservação e recuperação (R.R. Rodrigues \& H.F. Leitão Filho, eds.). EDUSP, São Paulo, p.45-71.
SCHIAVINI, I. 1997. Environmental characterization and groups of species in gallery forests. In International Symposium on Assessment and Monitoring of Forests in Tropical Dry Regions with Special Reference to Gallery Forests. (J. Imaña-Encinas \& C. Kleinn, coords.). Editora da Universidade de Brasília, Brasília, p.107-113.

SHEPHERD, G.J. 1994. FITOPAC 2.1: manual do usuário. Universidade Estadual de Campinas, Campinas.

SILVA JUNIOR, M.C. 1997. Relationships between the tree communities of the Pitoco, Monjolo and Taquara gallery forest and environmental factors. In International Symposium on Assessment and Monitoring of Forests in Tropical Dry Regions with Special Reference to Gallery Forests. (J. Imaña-Encinas \& C. Kleinn, coords.). Editora da Universidade de Brasília, Brasília, p.287-298.

SILVA JUNIOR, M.C., FURLEY, P.A. \& RATTER, J.A. 1996. Variation in the tree communities and soils with slope in gallery forest, Federal District, Brazil. In Advances in hillslope processes (M.G. Anderson \& S.M. Brooks, eds.). John Wiley \& Sons, London, v.1, p.451-469.

SOUZA, J.S. 2001. Análise das variações florísticas e estruturais da comunidade arbórea de um fragmento de floresta semidecídua às margens do rio Capivari, Lavras, MG. Dissertação de mestrado, Universidade Federal de Lavras, Lavras.

TER BRAAK, C.J.F. 1987. The analysis of vegetationenvironment relationship by canonical correspondence analysis. Vegetatio 69:69-77.

TER BRAAK, C.J.F. 1995. Ordination. In Data analysis in community and landscape ecology (R.H.G. Jongman, C.J.F. ter Braak \& O.F.R. van Tongeren, eds.). Cambrigde University Press, Cambrigde, p.91-173.

UHL, C. \& MURPHY, P.G. 1981. Composition, structure, and regeneration of a tierra firme forest in the Amazon Basin of Venezuela. Tropical Ecology 22:219-237.

VAN DEN BERG, E. \& OLIVEIRA FILHO, A.T. 1999. Spatial partitioning among tree species within an area of tropical montane gallery forest in south-eastern Brazil. Flora 194:249-246.

VAN DEN BERG, E. \& OLIVEIRA FILHO, A.T. 2000. Composição florística e fitossociologia de uma Floresta Estacional Semidecidual Montana em Itutinga, MG, e comparação com outras áreas. Revista Brasileira de Botânica 22:231-253.

VELOSO, H.P., RANGEL FILHO, A.L.R. \& LIMA, J.C.A. 1991. Classificação da vegetação brasileira adaptada a um sistema universal. Instituto Brasileiro de Geografia e Estatística, Rio de Janeiro.

WHITMORE, T.C. 1990. An introducion to tropical rain forests. Oxford University Press, Oxford.

ZAR, J.H. 1996. Biostatistical analysis, $3^{\text {a }}$ ed. Prentice Hall, New Jersey. 